\title{
Comparing the Effects of Subchronic Phencyclidine and Medial Prefrontal Cortex Lesions on Cognitive Tests Relevant to Schizophrenia
}

\begin{tabular}{|r|l|}
\hline Journal: & Psychopharmacology \\
\hline Manuscript ID: & Psych-2015-00226.R2 \\
\hline Manuscript Type: & Original Investigation \\
\hline Date Submitted by the Author: & O1-Jul-2015 \\
\hline Complete List of Authors: & $\begin{array}{l}\text { McAllister, Kathryn; The University of Cambridge, Department of } \\
\text { Psychology; The University of Cambridge, MRC and Wellcome Trust } \\
\text { Behavioural and Clinical Neuroscience Institute } \\
\text { Mar, Adam; The University of Cambridge, Department of Psychology; The } \\
\text { University of Cambridge, MRC and Wellcome Trust Behavioural and Clinical } \\
\text { Neuroscience Institute } \\
\text { Theobald, David; The University of Cambridge, Department of Psychology; } \\
\text { The University of Cambridge, MRC and Wellcome Trust Behavioural and } \\
\text { Clinical Neuroscience Institute } \\
\text { Saksida, Lisa; The University of Cambridge, Department of Psychology; } \\
\text { The University of Cambridge, MRC and Wellcome Trust Behavioural and } \\
\text { Clinical Neuroscience Institute } \\
\text { Bussey, Timothy; The University of Cambridge, Department of Psychology; } \\
\text { The University of Cambridge, MRC and Wellcome Trust Behavioural and } \\
\text { Clinical Neuroscience Institute }\end{array}$ \\
\hline Keywords: & $\begin{array}{l}\text { SCHIZOPHRENIA, PHENCYCLIDINE, PREFRONTAL CORTEX, OBJECT } \\
\text { RECOGNITION, RAT, ANIMAL MODEL, ASSOCIATIVE LEARNING, } \\
\text { GLUTAMATE, LEARNING AND MEMORY, DISCRIMINATION }\end{array}$ \\
\hline
\end{tabular}


Comparing the Effects of Subchronic Phencyclidine and Medial Prefrontal Cortex Dysfunction on Cognitive Tests Relevant to Schizophrenia

\author{
McAllister KAL ${ }^{a b}$, Mar $A C^{a b}$, Theobald DE ${ }^{a b}$, Saksida $L^{a, b}$, Bussey TJ ${ }^{a, b}$ \\ aUniversity of Cambridge Department of Psychology, Downing Street, \\ Cambridge, CB2 3EB, UK \\ ${ }^{\mathrm{b}} \mathrm{MRC}$ and Wellcome Trust Behavioural and Clinical Neuroscience Institute, \\ University of Cambridge, Cambridge CB2 3EB, UK
}

Acknowledgements: KAL McAllister received funding from the Cambridge Commonwealth Trusts and University of Cambridge Overseas Studentship Programme. LM Saksida and TJ Bussey also received funding from the Innovative Medicine Initiative Joint Undertaking under grant agreement no 115008 of which resources are composed of EFPIA in-kind contribution and financial contribution from the European Union's Seventh Framework Programme (FP7/2007-2013).

Disclosures: LMS and TJB consult for Campden Instruments Ltd.

Communicating author:

$\mathrm{KAL}$ McAllister

20 Manchester Sq.

London, UK, W1U 3PZ

kalmcallister@gmail.com

+44(0)7898989195 


\section{Abstract}

Rationale

It is becoming increasingly clear that the development of treatments for cognitive symptoms of schizophrenia requires urgent attention, and that valid animal models of relevant impairments are required. With subchronic PCP (scPCP) a putative model of such impairment, the extent to which changes following SCPCP do or do not resemble those following dysfunction of the prefrontal cortex is of importance.

\section{Objectives}

The present study carried out a comparison of the most common scPCP dosing regimen with excitotoxin-induced medial prefrontal cortex (mPFC) dysfunction in the rat, across several cognitive tests relevant to schizophrenia.

\section{Methods}

ScPCP subjects were dosed i.p. with $5 \mathrm{mg} / \mathrm{kg}$ PCP or vehicle twice daily for one week followed by 1 week washout prior to behavioural testing. mPFC dysfunction was induced via fibre-sparing excitotoxin infused into the prelimbic and infralimbic cortex. Subjects were tested on spontaneous novel object recognition, touchscreen object-location paired-associates learning, and touchscreen reversal learning.

\section{Results}

A double-dissociation was observed between object-location pairedassociates learning and object recognition: mPFC dysfunction impaired acquisition of the object-location task, but not spontaneous novel object recognition, while ScPCP impaired spontaneous novel object recognition, but not object-location associative learning. Both scPCP and MPFC dysfunction resulted in a similar facilitation of reversal learning.

\section{Conclusions}

The pattern of impairment following scPCP raises questions around its efficacy as a model of cognitive impairment in schizophrenia, particularly if importance is placed on faithfully replicating the effects of mPFC dysfunction. 
Introduction

It is becoming increasingly clear that the development of treatments for the cognitive symptoms of schizophrenia requires urgent attention (Minzenberg and Carter 2012; Schaefer et al. 2013; Vingerhoets et al. 2013). To achieve this aim we need valid animal models of the cognitive impairments in schizophrenia (Nestler and Hyman 2010). The psychotomimetic agent phencyclidine (PCP) has been widely used to model schizophrenia in rodents (Castner et al. 2004; Neill et al. 2010). In humans, PCP and other N-methyl$\mathrm{D}$-aspartate receptor (NMDAR) antagonists can induce the symptoms of schizophrenia and cause relapse for schizophrenics stabilized on antipsychotic medication (Itil et al. 1967; Javitt and Zukin 1991; Krystal et al. 1994; Lahti et al. 1995 \& 2001; Malhotra et al. 1996 \& 1997; Snyder 1980; Tamminga 1998). These observations are consistent with the 'glutamate hypothesis of schizophrenia', which posits that NMDAR function is disrupted in schizophrenia (Javitt et al. 2012; Poels et al. 2014; Singh and Singh 2011).

Subchronic PCP (scPCP) in particular has many prima facie advantages. For example, cognitive impairments relevant to schizophrenia have been observed following ScPCP (Arnt et al. 2010; Barnes et al. 2012; Beninger et al. 2010; Howes et al. 2015; Laurent and Podhorna 2004; McKibben et al. 2010; Meltzer et al. 2013) and the model, like other subchronic treatments, allows assessment of the effects of the treatment when the drug is no longer 'on board', thus minimizing motoric and/or motivational changes which can seriously confound cognitive testing and subsequent interpretation of the results.

Another attraction of the scPCP model is the assumption that it induces dysfunction of the prefrontal cortex (Amitai et al. 2012; Young et al. 2015), a major feature of the schizophrenic brain often cited as a major contributor to cognitive deficits (Glahn et al. 2005; Hill et al. 2004; Ingvar and Franzen 1974). Therefore the extent to which changes following scPCP do or do not resemble those found following dysfunction of the prefrontal cortex is of some importance to researchers in this area. Therefore in the present study we carried out a head-to-head comparison of the effects of the most common scPCP dosing regimen $(5 \mathrm{mg} / \mathrm{kg}$ twice daily for seven days followed by 7 days washout), with the effects of fibre-sparing excitotoxin-induced medial prefrontal cortex (mPFC) dysfunction in the rat, across several cognitive tests relevant to schizophrenia: object-location paired-associates learning, spontaneous novel object recognition, and reversal learning.

Object-location learning (Experiment 1):Object-location learning, for example as studied using the CANTAB PAL test (Sahakian et al. 1988), can be used to investigate the MATRICS domain of visual learning and memory and the CNTRICS domain of long term memory. Impairments in objectlocation paired-associates learning (PAL) have been found in chronic schizophrenia (Aubin et al. 2009; Donohoe et al. 2008; Haring et al. 2014; Wood et al. 2002) and can also be present at first onset of the disorder and may predict following clinical severity (Barnett et al. 2005). Additionally, impairments on CANTAB PAL have been observed during the prodromal phase and may be present in relatives at risk of developing schizophrenia 
(Bartok et al. 2005). Normal performance of CANTAB PAL depends on the medial temporal lobe (Wood et al. 2002) and prefrontal cortex (Owen et al. 1995).

The rodent object-location paired-associates learning task (PAL) was inspired by the CANTAB PAL task (Talpos et al. 2009) and has been recommended by CNTRICS for studying long-term memory in animal models of schizophrenia (Bussey et al. 2013).

Object Recognition (Experiment 2). Spontaneous Object Recognition (SOR) has been used to examine non-spatial memory impairments linked to schizophrenia (Dere et al. 2007; Lyon et al. 2012). In studies of SOR and scPCP immediately post-washout, significant impairments were observed following various retention periods (Arnt et al. 2010; Horiguchi et al. 2011; McKibben et al. 2010; Snigdha et al. 2010). Additionally, object recognition impairments following scPCP are attenuated by clozapine and risperidone, but not haloperidol (Grayson et al. 2007).

Reversal Learning (Experiment 3): Reversal learning assesses the subject's ability to acquire a simple 'rule' and then adopt a new strategy when the rule no longer holds. Reversal learning is impaired in schizophrenia (Leeson et al. 2009; McKirdy et al. 2009; Murray et al. 2008; Waltz and Gold 2007) and has been recommended by CNTRICS for studying executive function in animal models of schizophrenia (Gilmour et al. 2013). First, rats learn to discriminate between an $\mathrm{S}+$ and $\mathrm{S}$ - by perceptually discriminating between $\mathrm{S}+$ and $\mathrm{S}$ - and learning the reward contingency. Once the subject has acquired the discrimination, the reward contingency is reversed (S+ becomes the S-). The reversal stage requires the subject to inhibit responding to the previously rewarded stimulus, and switch to the new reward contingencies.

Reversal learning ability is dependent on the orbitofronal cortex (Bissonette et al. 2008; Burke et al. 2009; Chudasama and Robbins 2003) and striatum (Ragozzino 2007; Ragozzino et al. 2002). Previous studies have found impairments in reversal learning in schizophrenia (McKirdy et al. 2009; Murray et al. 2008; Schlagenhauf et al. 2014; Waltz and Gold 2007), which are present following correction for IQ (Leeson et al. 2009), consistent with hypofrontality in schizophrenia.

\section{Methods}

Apparatus: Rat touchscreen chambers were the same as those used in previous touchscreen studies (McAllister et al 2013; Bussey et al 2008; Talpos et al 2010). The object recognition Y-maze apparatus was the same as used by Forwood et al. (2005) and Winters et al. (2004). Three identical copies were used of each object with no natural significance or previous presentation.

Surgery: mPFC lesions generally followed the adaptation of Birrell and Brown's protocol (2000), used in previous touchscreen studies centred on prelimbic and infralimbic cortex (McAllister et al 2013). Bilateral injections of 
$0.2 \mu \mathrm{L}$ of $0.06 \mathrm{M}$ ibotenic acid (Sigma, UK) or vehicle were made at $\mathrm{AP}+3.5, \mathrm{~L}$ $\pm 0.6, \mathrm{~V}-5.2 ; \mathrm{AP}+2.5, \mathrm{~L} \pm 0.6, \mathrm{~V}-5.0 \mathrm{~mm}$, relative to skull surface Bregma via custom infusing line and $10 \mu \mathrm{L}$ Hamilton syringe and Harvard Instruments Pump 11 (Holliston, Massachusetts) pump. Subjects recovered for at least one week with ad libitum food and water prior to behavioural testing.

Histology: Protocol followed previous touchscreen studies of lesions centred on mPFC (McAllister et al 2013). Coronal sections $(60 \mu \mathrm{m})$ were stained with NeuN and lesion locations were mapped onto standardized sections of the (Paxinos and Watson 2007) atlas of the rat brain.

Subchronic Phencyclidine Protocol: Rats were dosed with $5 \mathrm{mg} / \mathrm{kg}$ PCP (Sigma, UK) via intraperitoneal injection $(5 \mathrm{mg} / \mathrm{ml})$ or $1 \mathrm{ml} / \mathrm{kg}$ vehicle twice daily $(7: 30 \mathrm{am} / \mathrm{pm})$ for seven days, followed by a seven-day washout period prior to behavioural testing.

Touchscreen Testing Protocol: Rats were group-housed on a reverse light-dark schedule (light 7pm-7am) and tested during dark phase. A restricted diet maintained rats at no less than $85 \%$ of free-feeding weight, with water available ad libitum. Pretraining touchscreen use prior to objectlocation or reversal learning tasks followed established protocols (Bussey et al. 2008; Horner et al. 2013; McAllister et al 2013). This experiment was conducted in accordance with the United Kingdom Animals (Scientific Procedures) Act, 1986.

\section{Object-location learning (Experiment 1)}

scPCP treatment: 16 male $250-275 \mathrm{~g}$ Lister Hooded rats were obtained from Harlan, UK. After completion of pretraining rats were pseudorandomly allocated to PCP or vehicle treatment groups. Following scPCP protocol rats completed two days of 'punish for incorrect' pretaining at criterion levels before PAL acquisition. PAL acquisition generally followed protocols established by Talpos et al (2009) with the exception that rats were tested twice daily over 11 blocks of 5 sessions each.

mPFC lesions: 16 male 250-275g Lister Hooded rats were obtained from Harlan, UK. Behavioural methods were initially identical to those in Experiment $1 \mathrm{scPCP}$, but as a difference between groups was observed, testing was extended to 17 blocks to explore the persistence of the deficit. Following acquisition of dPAL, an object-location challenge took place: the foil stimulus was replaced with the correct stimulus for all trials (sPAL protocol; Talpos et al., 2009; figure 1).

Behavioural testing: In this task three images are used as objects, each correct when presented in one of three response locations, and incorrect when presented in either of the other two. There are six unique trial types of one object in its correct location and a different foil object in an incorrect location (the 'dPAL' version of the task; Talpos et al 2009, figure 1). Talpos et al (2009) demonstrated that pharmacological manipulations of the hippocampus could impair performance of PAL, consistent with human imaging studies showing the hippocampus activated during encoding and parahippocampal gyrus during retrieval of the CANTAB PAL task (de Rover et 
al. 2011). Dependency on mPFC has not previously been investigated. In this first experiment, we tested the effects of SCPCP on the touchscreen PAL test.

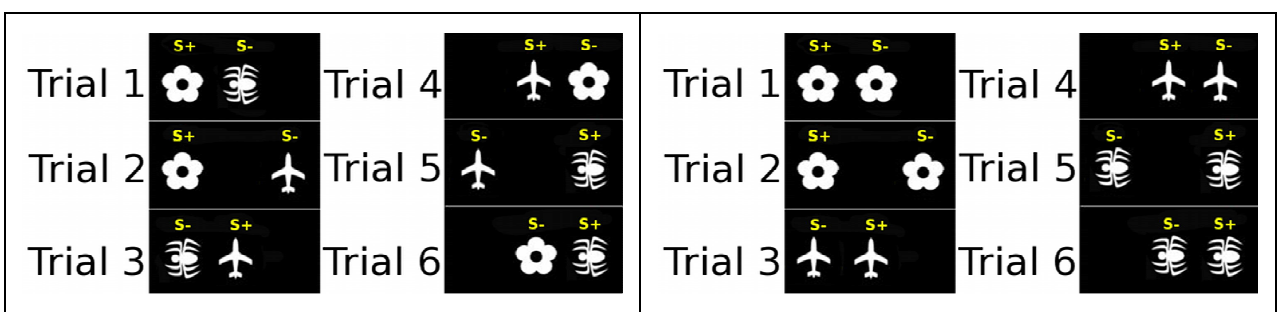

Fig. 1 Trial-types in touchscreen object-location paired-associates learning (dPAL left and SPAL right). S+ rewarded; S- results in 'time out'. Adapted from Talpos et al (2009).

\section{Object recognition (Experiment 2)}

The same scPCP and mPFC rats were used as in Experiment 1 and maintained under the same housing conditions. Experiment 2 took place immediately following PAL acquisition, with initial habituation beginning the day following the last session of PAL.

Three daily 5-minute habituation sessions followed by two sets of discriminations with novel object, order and novel side counterbalanced. Discrimination trials consisted of 3-minute exposure to 2 copies of the same object (sample phase), delay, then 3-minute choice phase with a third copy of the pre-exposed object and a novel object. The apparatus and objects were wiped down with a dilute ethanol solution between trials to prevent olfactory trails. A minimum of 20 seconds exploration during sample phase was required for analysis, defined as nose oriented towards the object within $2 \mathrm{~cm}$. Discrimination scores
well as the first minute.

In addition, this experiment allowed testing of the persistence of the functional effects of scPCP, as it is conceivable that the lack of effect of sCPCP on PAL in Experiment 1 was due to the effects of SCPCP decreasing over time. Indeed, longitudinal testing of the effects of SCPCP post-washout is not common, with most testing taking place fewer than seven days postwashout. Thus we tested the same rats used in Experiment 1 on spontaneous object recognition at 2 time-points: 40 and 105 days postwashout.

\section{Reversal learning (Experiment 3)}

32 male $250-275 \mathrm{~g}$ Lister Hooded rats were obtained from Harlan, UK and housed as in PAL protocol, above.

Behavioural testing took place in the touchscreen chambers used in Experiment 1, with screen masking adapted for 2 choices. Acquisition 
consisted of daily 1 hour sessions of up to 100 trials until all subjects reached stable criterion of greater than $80 \%$ across 3 consecutive days. Subjects were pseudorandomly assigned to treatment groups, counterbalancing for performance. All rats immediately re-baselined at criterion and reversal began on day 4 post-washout/11 post-lesion. Maximum session length was 100 trials or 1 hour, with the first session split into shorter sessions of 25, 25, and 50 trials (one session/day) to ensure completion of trials (summed to session 1). Rats were tested for 18 sessions.

\section{Results}

Experiment 1: Effects of SCPCP on acquisition of the PAL task

Repeated-measures ANOVA did not demonstrate a significant effect of scPCP in acquisition of object-location paired-associates learning $\left(\mathrm{F}_{(1-14)}\right)$ $0.675, p=0.43$ ) and both groups reached $80 \%$ correct by block 11 . At this point, rats moved on to Experiment 2. Log transformed reaction times significantly decreased across acquisition $(F(2.37,33.12)=16.31, p<0.001)$ with no significant effect of $\operatorname{scPCP}(F(1,14)=0.89, p=0.361)$. Magazine latency also decreased across acquisition $\left(F_{(10,14)}=2.67, p=0.005\right)$, with no significant effect of $\operatorname{scPCP}(F(1,14)=0.11, p=0.92)$.

\section{PCP and PAL Acquisition}

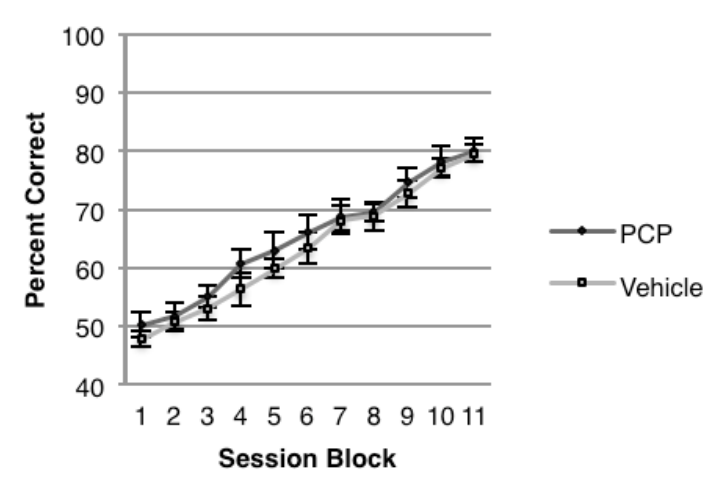

Fig. 2 Effects of scPCP on acquisition of PAL. Blocks of 5 sessions are plotted. Error bars \pm 1 SEM.

\section{Experiment 1: mPFC Dysfunction and PAL Acquisition}

Histological results: Histology confirmed lesions of the medial prefrontal cortex in all rats, centred on the prelimbic and infralimbic cortices with damage to overlying anterior cingulate cortex. Shams did not show significant damage to any of those regions. One lesion was excluded from data analysis as largely unilateral, resulting in 8 sham and 7 lesions. 

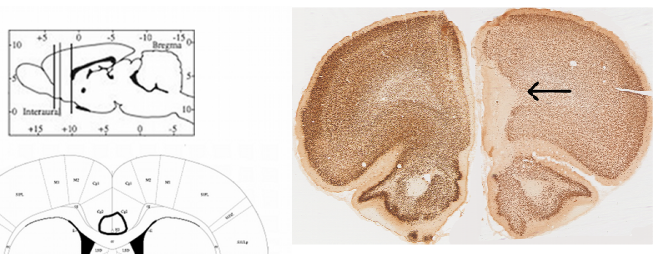

Fig. 3 mPFC lesions in PAL. Damage common to all subjects in solid black, with maximum extent of any damage shown by the black line. Coronal sections at $3.72 \mathrm{~mm}$, $2.76 \mathrm{~mm}$, and $1.08 \mathrm{~mm}$ anterior to Bregma. Images adapted from Paxinos and Watson (2007). Composite photomicrograph presents contrast between sham (left) and lesion (right) for demonstration purposes.

Behavioural results: Repeated measures ANOVA demonstrated significant main effect of lesion $(F(1,12)=5.01, p=0.045)$ and session block $(F(7.87,54)=63.8, p<0.001)$, with no interaction $(F(7.87,54)=1.74, p=0.099)$. Performance appeared to asymptote slightly below $90 \%$ correct for shams, and $80 \%$ correct for lesions (no significant learning over blocks 17-19: shams $(F(2,12)=0.25, p=0.78$; lesion $F(2,12)=0.23, p=0.80)$. Response latencies reduced over the course of acquisition $(F(7.42,81.6)=1.94,<0.001)$, with no significant difference between sham and lesion $(F(1,11)=1.46, p=0.25$ or latency to magazine $(F(1,11)=0.32, p=0.86)$.

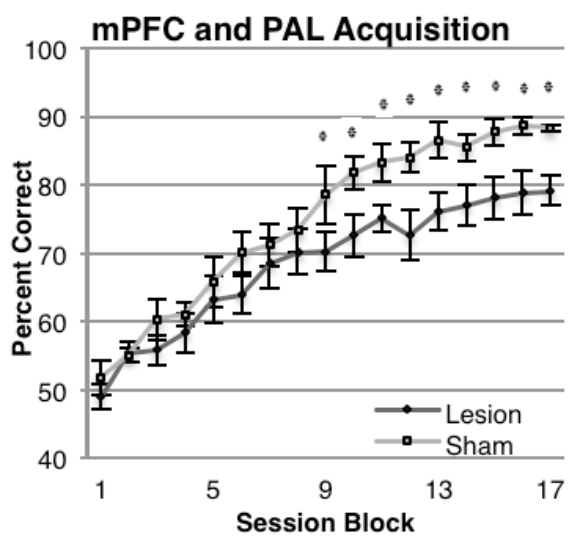

Trial-Type Standard Deviation

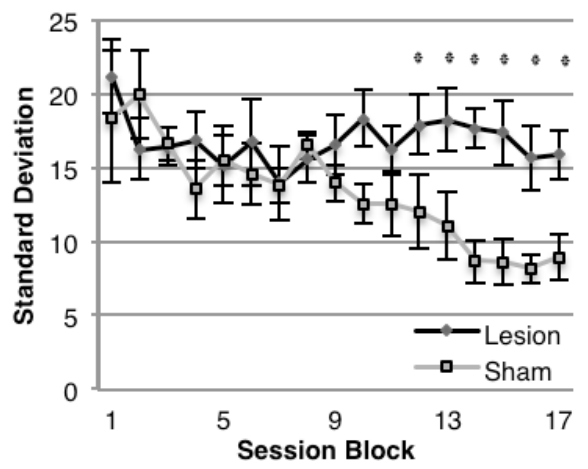




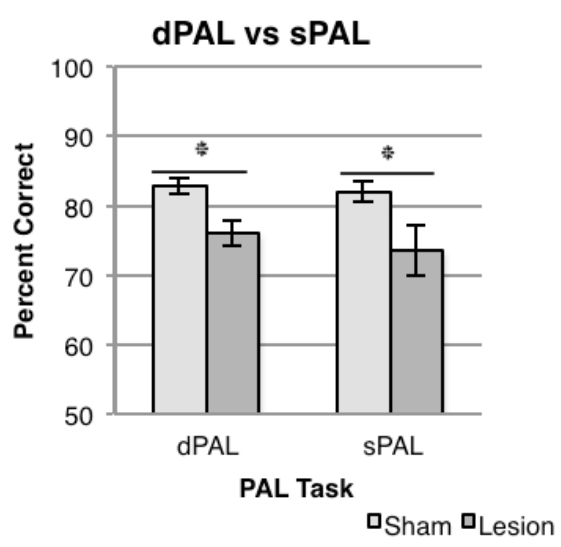

Fig. 4 Effects of mPFC

dysfunction on acquisition of PAL and SPAL object-location challenge. Blocks of 5 sessions are plotted. Error bars \pm 1 SEM. $*=p<0.05(\mathrm{~S}-\mathrm{N}-\mathrm{K})$. A significant difference in standard deviation of performance between trial-types during PAL acquisition.

During the $\mathrm{mPFC}$ object-location challenge, there was no significant difference in performance between dPAL and sPAL for sham $\left(t_{(12)}=0.46\right.$, $p=0.65)$ or lesion $\left(t_{(12)}=0.59, p=0.56\right)$, suggesting both groups used an objectlocation strategy (rather than, e.g., a conditional strategy). The lesion group was impaired on both sPAL and dPAL $\left(\mathrm{dPAL}_{(12)}=3.05, \mathrm{p}=0.01\right.$; $\mathrm{sPAL}$ $\left.t_{(12)}=2.14, p=0.044\right)$. To further probe the nature of task acquisition, analysis of individual trial types was then undertaken.

Analysis showed different rates of learning of each trial-type-- not unexpected, as it is likely an animal would, for various reasons, work out some of the object-location bindings before others. Interestingly, however, initial examination by trial-type across acquisition found greater variance in the lesion group versus shams, suggesting that the lesion group had not fully solved all of the object-location paired-associates.

To quantify this variability we calculated, for each rat, mean standard deviation on each of the 6 trial types throughout acquisition (figure 4). There was a significant effect of block (ANOVA $F_{(8.4,108)}=2.94, p<.01$ ) and a significant lesion $x$ block interaction $\left(F_{(8.4,108)}=2.53, p=0.01\right)$ as the sham group learned to perform all trial-types with greater proficiency, whereas the rats in the lesion group learned some trial types but not others.

\section{Experiment 2: scPCP and Object Recognition}

Both 1 minute and 3 minute discrimination scores showed significant decrease in preference for the novel object in the scPCP group at six but not fifteen weeks post-washout (figure 5). There was no significant difference between sham and lesion in overall exploration time during sample or choice at six weeks (sample $t_{(12)}=0.086, p=0.51$; choice $t_{(12)}=0.82, p=0.43$ ). scPCP significantly impaired novel object recognition at a 1 hour delay compared to vehicle $t_{(12)}=2.55, p<0.01$, with the scPCP discrimination score not significantly greater than chance $\left(\mathrm{t}_{(6)}=1.69, \mathrm{p}=0.14\right)$. 
scPCP and Object

Recognition

(40 Days Post-washout)

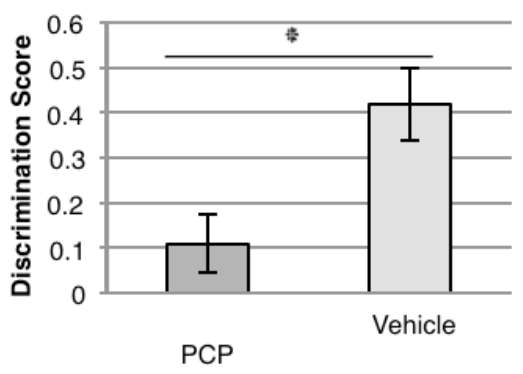

scPCP and Object

Recognition

(105 Days Post-washout)

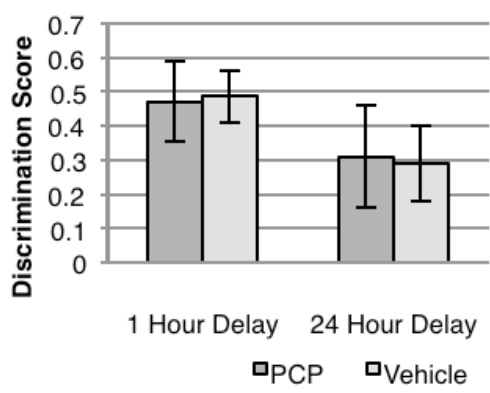

Fig. 5 ScPCP and object recognition 40 and 105 days post-washout. Means of first minute discrimination scores. \pm 1 SEM. ${ }^{*}=p<0.01$.

Re-testing three months (105 days) post washout found no impairment in SCPCP at a 1 hour or 24 hour delay (figure $5 ; 1$ hour $\mathrm{t}_{(12)}=0.05, \mathrm{p}=0.95 ; 24$ hour $t_{(12)}=0.07 p=0.92$ ), and no difference in exploration time (1 hour sample: $\mathrm{t}_{(12)}=1.21, \mathrm{p}=0.25$, choice: $\mathrm{t}_{(12)}=1.43, \mathrm{p}=0.18 ; 24$ hour sample $\mathrm{t}_{(12)}=0.74, \mathrm{p}=$ 0.47 , choice $\left.t_{(12)}=0.32, p=0.75\right)$.

\section{Experiment 2: mPFC Dysfunction and Object Recognition}

1 minute and 3 minute discrimination scores showed no significant difference between lesion and sham rats at 1 hour or 24 hour delays ( 1 hour $\mathrm{t}_{(12)}=1.51, \mathrm{p}=0.62, \mathrm{t}_{(.02)}=0.98$ or 24 hour $_{(12)}=0.93, \mathrm{p}=0.37, \mathrm{t}_{(12)}=0.55, \mathrm{p}=$ $0.60)$.

\section{mPFC Lesion and Object Recognition}

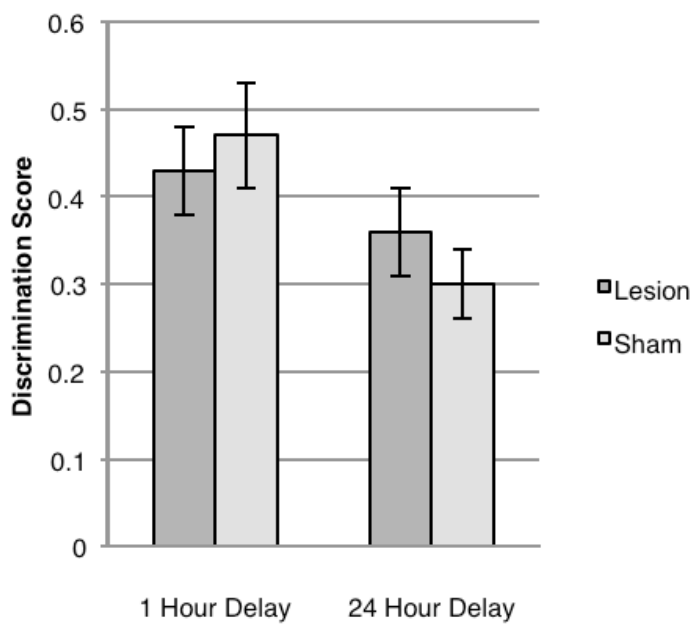


Fig. $6 \mathrm{mPFC}$ dysfunction and object recognition. Means of first minute discrimination scores. \pm 1 SEM.

There were no significant differences in exploration time in sample or choice phase at a 1 hour (sample: $\mathrm{t}_{(12)}=1.53, \mathrm{p}=0.15$; choice: $\mathrm{t}_{(12)}=0.78, \mathrm{p}=$ 0.45 ) or 24 hour delay (sample: $\mathrm{t}_{(12)}=0.52, p=0.61$; choice: $\mathrm{t}_{(12)}=1.03$, $p=0.32$ ). Discrimination scores at the 24 hour delay were significantly greater

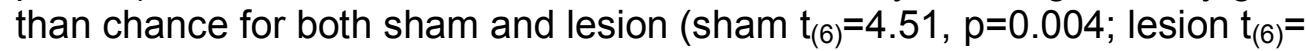
$3.14, p=0.016)$.

\section{Experiment 3: scPCP and Reversal Learning}

scPCP rats were significantly faster to reach the reversal learning criterion ( $80 \%$ accuracy over 2 consecutive sessions) than control rats both in errors to criterion $\left(t_{(14)}=1.78, p=0.048\right)$ and sessions to criterion $\left(t_{(14)}=1.95\right.$, $p=0.035$ ).

Performance across days of acquisition (figure 7 ) revealed a significant main effect of drug treatment on overall accuracy $\left(F_{(1,10)}=5.2, p=0.046\right)$ and number of correction trials $\left(F_{(1,10)}=6.4, p=0.03\right)$ but no drug $x$ session interactions (accuracy $\mathrm{F}_{(8.09,80.9)}=0.58, p=0.77$, correction trials $\mathrm{F}_{(3.91,39.2)}=$ 0.95, $p=0.44)$.
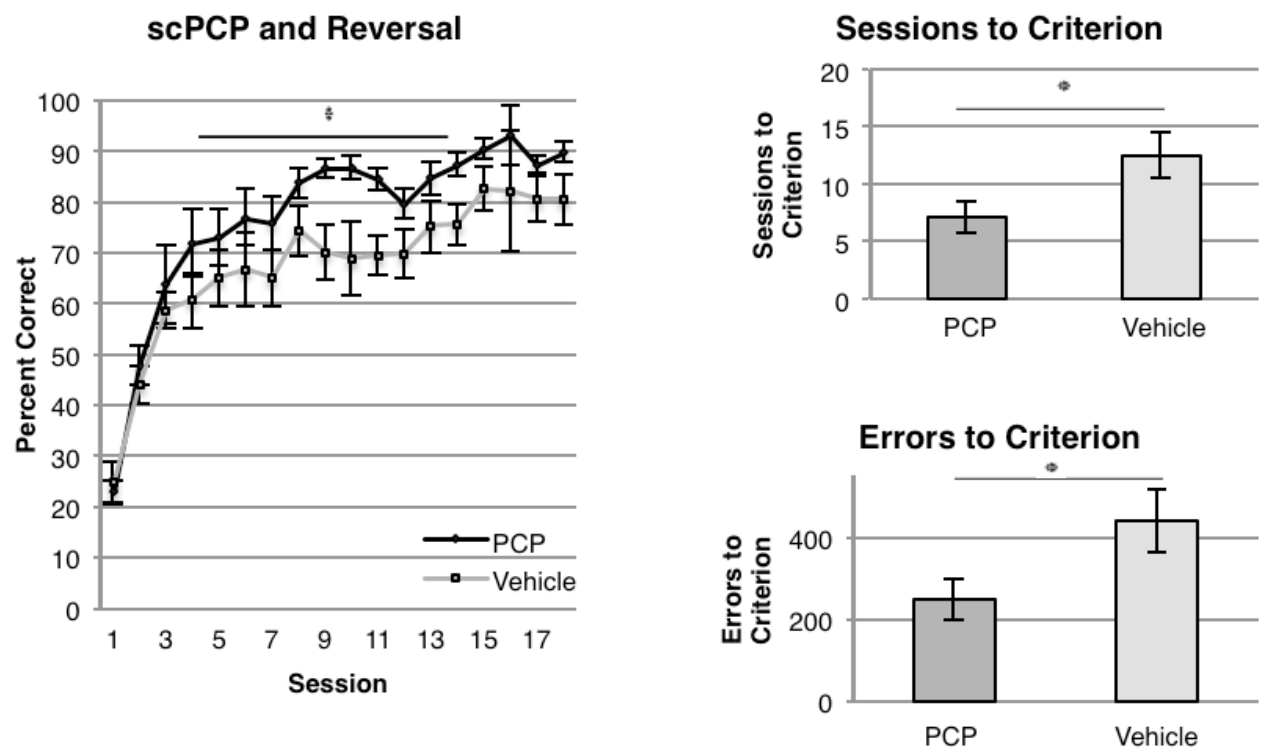

Fig. 7 Effects of scPCP on reversal learning acquisition, sessions and errors to criterion. Means \pm 1 SEM. ${ }^{*}=p<0.05$.

Analysis was also conducted in terms of stage of reversal, through early sessions (sessions 1-2), and mid-late sessions (considering sessions 36 and 7-18 independently gave the same results as pooling). There was no 
significant difference in accuracy or number of correction trials in early trials (accuracy $F_{(1,13)}=0.068, p=0.799$; correction trials $F_{(1,14)}=2.11, p=0.17$ ), but the effect of SCPCP on accuracy was significant through mid-late sessions $\left(F_{(1,10)}=4.93, p=0.041\right)$. Analysis of the perseveration index, the ratio of correction trials to initially incorrect responses, showed no significant difference overall $\left(F_{(1,10)}=1.17, p=0.30\right)$ or in early sessions $\left(F_{(1,10)}=4.62, p=\right.$ $0.067)$ between sham and lesion.

A significant effect of drug treatment on log transformed response latency was seen in early sessions $\left(F_{(1,10)}=5.71, p=0.038\right)$ with vehicle rats initially responding significantly more rapidly. This initial difference was not observed through later sessions $F_{(1,10)}=4.23, p=0.67$ ) and there was no significant drug $x$ session interaction $\left.F_{(5.89,70.74)}=1.74, p=0.60\right)$. No significant effect of drug was seen on log transformed magazine latency in early sessions $\left(F_{(1,10)}=0.20, p=0.664\right)$, late sessions $\left(F_{(1,10)}=2.03, p=0.184\right)$, or overall $\left(F_{(1,10)}=1.79, p=0.210\right)$.

\section{Experiment 3: mPFC Dysfunction and Reversal Learning}

Histological results: Analysis of histology confirmed lesions of the medial prefrontal cortex in all rats, centred on the prelimbic cortex, with damage to the infralimbic cortex and overlying anterior cingulate (figure 8 . Sham animals did not show damage to any of those regions, and one lesioned animal was excluded due to more unilateral lesion than common.
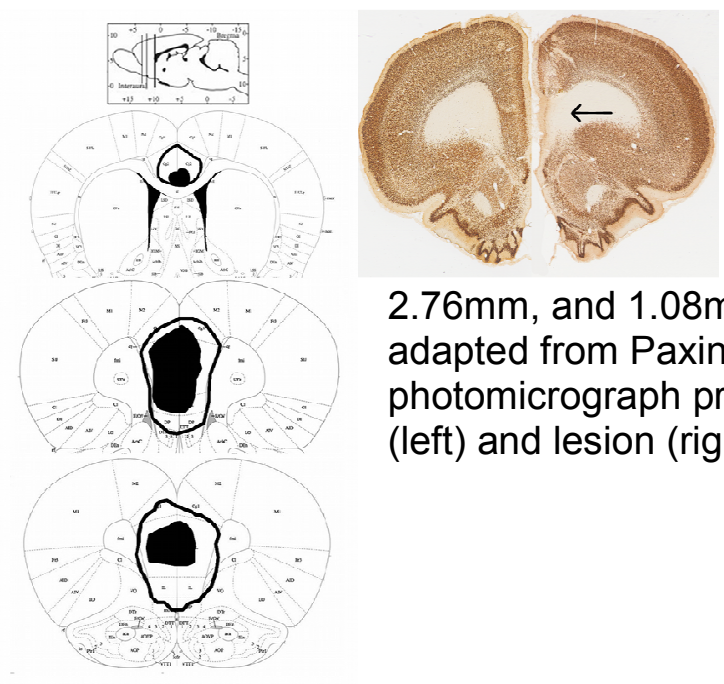

Fig. 8 mPFC lesions in reversal learning. Damage common to all subjects in solid black, with maximum extent of any damage shown by the black line. Coronal sections taken at $3.72 \mathrm{~mm}$, $2.76 \mathrm{~mm}$, and $1.08 \mathrm{~mm}$ anterior to Bregma. Images adapted from Paxinos and Watson (2007). Composite photomicrograph presents a contrast between sham (left) and lesion (right) for demonstration purposes.

Behavioural results: Rats were rebaselined for three sessions of the original discrimination post-surgery, which all subjects completed at criterion level $(>80 \%)$. mPFC rats were significantly faster in number of sessions required to reach the reversal learning criterion $\left(t_{(12)}=2.52, p=0.013\right)$, and also showed a near-significant reduction in the number of errors to criterion $\left(t_{(12)}=1.71, p=0.056\right)$. 

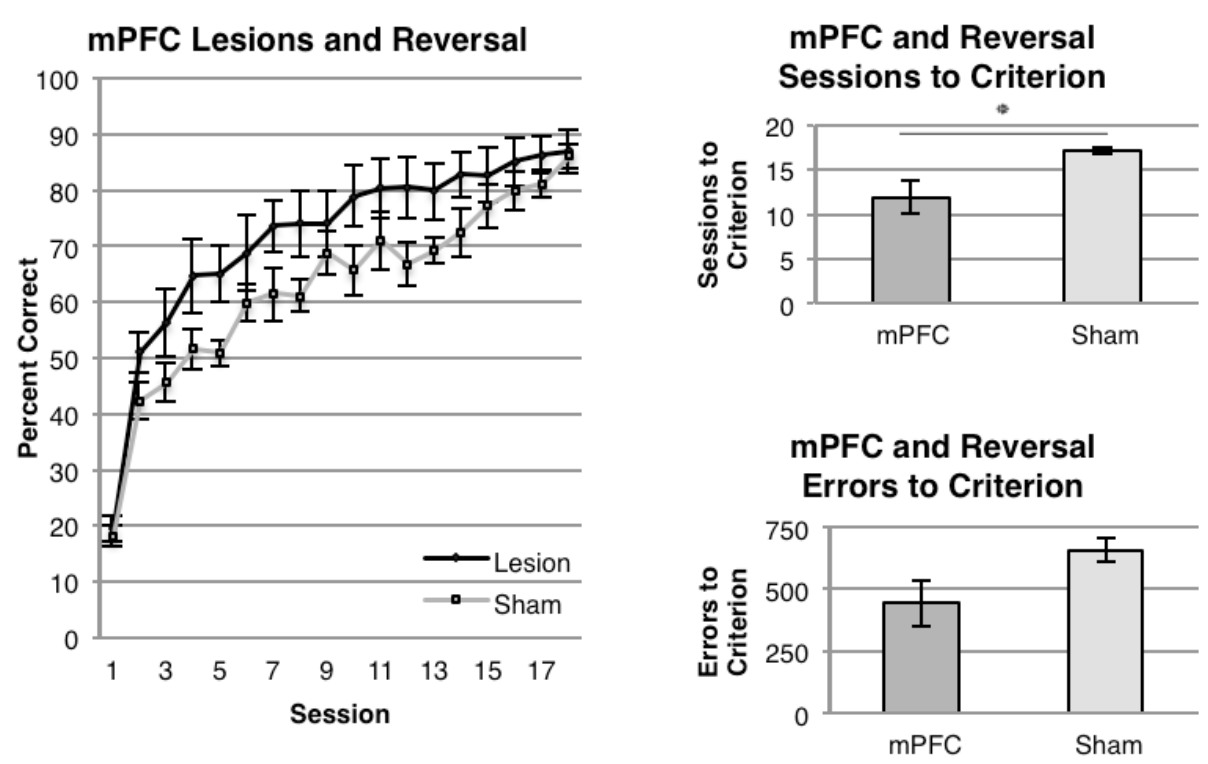

Fig. 9 Effects of mPFC lesions on reversal learning; errors and sessions to criterion. Means \pm 1 SEM. ${ }^{*}=p<0.05$.

Analysis of accuracy over the course of reversal found no significant effect of lesion during early trials $\left(F_{(1,11)}=4.18, p=0.086\right)$, mid trials $(3-6)$ $\left.F_{(1,11)}=4.12, p=0.067\right)$, late trials $\left.(7-18) F_{(1,11)}=2.57, p=0.14\right)$ or across midlate sessions $\left(F_{(1,11)}=3.2, p=0.10\right)$. There was no significant difference in number of correction trials in early trials only $\left(F_{(1,11)}=0.53, p=0.48\right)$ or midlate trials only $\left(F_{(1,11)}=2.22, p=0.16\right)$.

The perseveration index showed no significant effect of lesion $\left(F_{(1,10)}=0.44, p=0.52\right)$. There was no difference in reaction time $\left(F_{(1,11)}=\right.$ $0.074, p=0.79$ ) with reaction time decreasing as the reversal progressed $\left(F_{(7.7,84.9)}=34.1, p<0.001\right)$. There was no effect of lesion on magazine latency $\left(F_{(1,11)}=0.001, p=0.98\right)$ with latency roughly remaining constant as the reversal progressed in both groups $\left(F_{(1.23,13.53)}=4.01, p=0.059\right)$.

\section{Discussion}

There was a double-dissociation between object-location pairedassociates learning and object recognition: mPFC dysfunction impaired acquisition of the object-location task, but not spontaneous novel object recognition, while sCPCP impaired spontaneous novel object recognition, but not object-location associative learning. Both scPCP and mPFC dysfunction resulted in a similar facilitation during the late stages of reversal learning. 


\begin{tabular}{|l|c|c|}
\hline & scPCP & mPFC Lesion \\
\hline $\begin{array}{l}\text { Object-Location Paired-Associates } \\
\text { Learning: Acquisition }\end{array}$ & No effect & Impairment \\
\hline $\begin{array}{l}\text { Object-Location Paired-Associates } \\
\text { Learning: Motivation/Latencies }\end{array}$ & No effect & No effect \\
\hline Object Recognition: Discrimination & Impairment & No Effect \\
\hline Object Recognition: Exploration & No effect & No effect \\
\hline Reversal Learning & Facilitation & Facilitation \\
\hline
\end{tabular}

Table 1 Cognitive profiles of scPCP and mPFC lesions generated in the present study.

\section{Object-location learning (Experiment 1)}

Whereas most tests of cognitive function following ScPCP are conducted immediately post-washout, observed impairments on object recognition following PAL acquisition indicate the lack of effect of ScPCP on PAL was not due to a decrease in general efficacy of the manipulation across time.

Previous studies have suggested that SCPCP can impair object-location learning. For example, $5 \mathrm{mg} / \mathrm{kg}$ SCPCP induced a deficit in rats' ability to simultaneously associate object-place-context (O-P-C) to identify novel objects (Le Cozannet et al. 2010). That task, however, relies on one-trial spontaneous object recognition (known to be impaired following SCPCP, see below). This lower-order failure could underlie the observed impairment in other studies of object-location learning.

While a significant main effect of lesion was observed, the effect of the lesion manifests as a selective impairment in the later stages of acquisition. To investigate further how this task is solved, and thus perhaps illuminate the impairment seen following mPFC dysfunction, we carried out an objectlocation challenge ('sPAL'; Talpos et al 2009). With only six unique trial types it is conceivable that animals were responding to trial types as a whole picture or scene (a 'gestalt') rather than individual objects situated in individual locations, perhaps applying conditional rules by trial type.

Correct object-location associations should result in completion of sPAL with little difficulty, whereas a strategy based on the combination of objects presented during the trial would not work. Analysis showed no impairment in either group switching to SPAL, suggesting that both sham and lesion groups were not using a 'gestalt' trial-type strategy. The mPFC group was still impaired relative to sham, and their performance on SPAL dropped roughly the same amount (but not to chance). This pattern suggests that the 
residual performance of $\mathrm{mPFC}$ lesioned group was due to some preserved object-location learning, but that this learning was not a rapid as in controls.

In addition, analysis of variability in performance across trial types was quite revealing: in sham animals, performance on the different trial-types was highly variable during first sessions, then appeared to briefly converge, before performance across all trial types increased more uniformly. This pattern may reflect a transition from an 'elemental' strategy, or perhaps stimulus bias (responding preferentially to particular stimuli), to an object-location configural/associative solution.

Interestingly, the PFC-lesioned rats showed a very different pattern of performance (figure 4). Like shams, rats in the PFC group appear to have approached the task with an elemental strategy or stimulus bias (indicated by the high variability across trial types during initial acquisition). The variance then decreases as rats relinquish this strategy or bias. Thereafter, however, performance differs markedly: whereas the sham animals' performance increases and the trial-type variance decreases, the mPFC rats' performance increases little and the variance remains the same. This pattern of results, and the pattern obtained in the SPAL probe analysis, suggest that in the later stages of PAL acquisition, rats master object-location associations, and that mPFC dysfunction impairs the ability to progress through this stage of the task. The idea that mPFC dysfunction impairs object-location binding is consistent with previous reports (Barker et al. 2007; Barker and Warburton 2011).

\section{Object Recognition (Experiment 2)}

scPCP treatment produced a robust impairment on object recognition in keeping with previous studies (Arnt et al. 2010; Grayson et al. 2014; Grayson et al. 2007; Horiguchi et al. 2011; Snigdha et al. 2010; Snigdha et al. 2011). This impairment is not the result of general differences in the exploration of objects, as evidenced by the roughly equal exploration times during the sample phase. The effects of scPCP treatment were shown to be surprisingly long-lasting, affecting SOR 40 days post washout. However, the effects of ScPCP was also time-limited, with no effect at even a 24 hour delay after 105 days. A caveat is that this comparison is made within-subject, without a between-subject control for order of testing. However it seems unlikely that the substantial difference between effects of SCPCP at 40 and 150 days was due to this factor alone.

The neurobiological changes underlying this impairment remain unclear, and myriad effects are observed following scPCP treatment (Egerton et al. 2005; Neill et al. 2010; Neill et al. 2014). In particular, studies have shown that SCPCP treatment downregulates striatal D1 and upregulates cortical 5-HT1A receptor binding in rats (Choi et al. 2009). Investigation of the amelioration of scPCP-induced impairments in novel object recognition implicate these mechanisms, as the D1 receptor agonist asenapine ameliorates a scPCP-induced impairment in object recognition, unless cotreated with the D1 antagonist SCH-23390 (Snigdha et al. 2011). Coadministration of atypical antipsychotics with PCP prevent development of 
novel object recognition deficits (Oyamada et al. 2015). Further studies with D1 agonists (McLean et al. 2009) or atypical antipsychotics (Grayson et al. 2007) have also demonstrated amelioration of impairments in object recognition. Additionally, the 5-HT6 receptor antagonist Lu AE58054 has been shown to rescue ScPCP induced impairment in object recognition (Arnt et al. 2010).

A lack of effect of mPFC lesions on object recognition is in keeping the literature published on various forms of spontaneous object recognition (Barker et al. 2007; Ennaceur et al. 1997; Hannesson et al. 2004).

\section{A double-dissocation between object-location learning and object recognition}

The effects of scPCP dissociated across tasks: while scPCP did not impair object-location paired-associates learning, it did impair spontaneous object recognition. This may appear paradoxical, as object recognition could seem to be required for paired-associates learning (for example, lesions to the perirhinal cortex impaired both object recognition and an object-in-place task (Barker and Warburton 2011), although perirhinal cortex lesions have not been tested with the touchscreen PAL task used here). However the repeated exposure to trial types and gradual learning in touchscreen paired-associates learning may be a fundamental difference between these tasks. Unlike object recognition, which is regarded (rightly or wrongly; Bussey et al. 2013) as onetrial learning, PAL was learned across sessions over many days. Perirhinal cortex dysfunction can impair discrimination learning across sessions in the touchscreen (Winters et al. 2010), although the photographic stimuli used in that study were more complex than those used here, and it has been shown that perirhinal lesions can impair complex, but not simple discriminations (Bussey et al. 2003). Another possibility is that ScPCP affected structures other than perirhinal cortex that are important for object recognition, for example mediodorsal thalamus (Aggleton and Mishkin 1983; Mumby et al. 1993).

The effects of mPFC cortex dysfunction were also observed to dissociate across tasks, but in the opposite direction: lesions impaired PAL, but not object recognition. This likely reflects the higher order nature of the PAL task, which requires integrating information about object and location. This interpretation is consistent with the findings of Barker et al (2007), who report impairment following PFC dysfunction on an object-location task (but not on simpler object or location recognition tasks).

Thus, Experiments 1 and 2 demonstrate a double dissociation between scPCP and PFC dysfunction on PAL and object recognition tasks. The object recognition data show that SCPCP affects structures outside the PFC that are important for object recognition. More surprisingly, perhaps, the PAL experiments show that if SCPCP induces mPFC dysfunction, it is not of sufficient magnitude to mimic the impairments found after excitotoxic mPFC dysfunction on this task.

Reversal learning (Experiment 3) 
Rodent models of schizophrenia have often demonstrated impaired acquisition, impaired reversal, and/or increased perseveration in various testing paradigms (Brigman et al. 2006 \& 2008; Zhuo et al. 2007). In contrast, in the present experiment, scPCP facilitated performance during the later sessions of reversal. scPCP-treated animals did not display any differences from vehicle-treated animals when performing below $50 \%$ correct, indicating that increased perseveration is not resulting from the ScPCP treatment.

While certain other models of schizophrenia have not displayed increased perseveration (e.g., Brigman et al. 2008), they have shown impaired learning of the new S+ v S- contingency. However, scPCP treatment did not impair acquisition or reversal of a visual discrimination in mice (Brigman et al. 2009) or rats (Fellini et al. 2014). Unlike these previous studies, in the present study performance during late reversal was actually facilitated, with PCP-treated rats reaching asymptote at a higher level of performance than their vehicle treated controls. However, selective late-stage facilitation has been previously observed in touchscreen reversal learning conducted under similar conditions. In mice, both mild stress and ventromedial prefrontal cortex lesions selectively facilitated late reversal (Graybeal et al. 2011). The authors note that in other studies chronic stress can promote habit-like responding in rats (coupled with atrophy of MPFC and the 'associative' striatum and hypertrophy of the 'sensorimotor' striatum, as in (Dias-Ferreira et al. 2009). Indeed, lesions of the dorsolateral striatum impaired touchscreen reversal in mice; see Graybeal et al (2011) supplementary materials. The effects of SCPCP might be understood using a similar explanation: dysfunction of the vmPFC removes inhibition on the dorsolateral striatum and thus facilitates striatal-mediated habit formation late in the reversal. However combined with the results from Experiment 1, such an explanation suggests that mPFC dysfunction induced by scPCP was sufficient to facilitate transition to habit, but insufficient to produce an impairment in PAL. Alternatively, other mechanisms such as direct disinhibition of the striatum might underlie the scPCP-induced improvement.

Like scPCP treatment, and consistent with previous studies, mPFC dysfunction did not impair reversal learning (Boulougouris et al. 2007; Chudasama et al. 2001) and indeed, according to sessions and errors to criterion, significantly facilitated it. Visual inspection indicates that like SCPCP, facilitation appears in the late, but not the early, perseverative stage of reversal. A difference between the pattern of data in the two experiments is that the (sham-lesioned) control rats eventually reached the same performance level as the mPFC-lesioned rats, whereas the vehicle-treated rats never quite reached the same level as the scPCP-treated rats. There was also more variability in the mPFC lesion group than there was in the scPCP-treated group. Taking these considerations into account, and the uncommon pattern of late reversal facilitation in both experiments, we conclude that the effects of SCPCP and mPFC dysfunction were similar. However neither manipulation looks like what one would expect from a 'complete' model of schizophrenia, in which reversal learning is, if anything, impaired (Leeson et al. 2009; Murray et al. 2008; Waltz and Gold 2007).

That mPFC dysfunction did not produce impairment in touchscreen reversal learning is consistent with previous literature (Bussey et al., 1997; 
although impairments were obtained with perceptually difficult stimuli). Previously, dissociations have been observed between regions of the prefrontal cortex: orbitofrontal cortex lesions impair reversal learning, while mPFC lesions impair attentional set shifting (Bissonette et al. 2013; Dias et al. 1996). Indeed, ventromedial prefrontal cortex (vmPFC) lesions in mice led to a late facilitation similar to that observed here (Graybeal et al. 2011). Coupled with the finding that BDNF infusions into the vmPFC prevent reversal facilitation by stress, and the effects of striatal lesions, Graybeal et al proposed a mechanism whereby vmPFC dysfunction disinhibits habit formation by striatal systems (see discussion of Experiment 3 above, (Graybeal et al. 2011). A similar mechanism may underlie the late facilitation seen in the ScPCP-treated rats, and/or the trend toward facilitation shown by the mPFC-lesioned rats, in the present study.

\section{Evaluating scPCP as a Model for Schizophrenia}

The use of phencyclidine to model schizophrenia has received some criticism (Brigman et al. 2010; Domino and Luby 2012). As schizophrenia is characterized by hypofunction of the prefrontal cortex (Andreasen et al. 1992; Carter et al. 1998; Glahn et al. 2005; Hill et al. 2004), in the present experiments we asked the specific question of whether the cognitive impairments following scPCP resemble those following mPFC dysfunction. These findings may be useful to consider when choosing a rodent model for studies into schizophrenia, particularly if importance is placed on the model faithfully reproducing the effects of mPFC dysfunction. Considering each of the three tasks in turn:

Object-location learning: Although scPCP had no effect on PAL, schizophrenic patients are impaired on the CANTAB version of PAL (Bartok et al. 2005). Great caution must be taken, however, in using this contrast alone to conclude that SCPCP is a poor model, as we do not yet have a complete idea to what extent rodent PAL and CANTAB-PAL depend on the same psychological and neural mechanisms. Although some evidence suggests they do, for example performance of rodent PAL and CANTAB-PAL both involve the hippocampus (de Rover et al. 2011; Owen et al. 1995; Talpos et al. 2008; Kim et al., this issue) and mutations in the schizophrenia-related gene dlg2 can lead to impairments in both rodent PAL and CANTAB-PAL (Nithianantharajah and Grant 2013). However, scPCP did not replicate the effects of mPFC dysfunction on this task.

Object Recognition: scPCP clearly and reproducibly impaired OR. Thus sCPCP combined with SOR may be a good model for testing schizophreniarelevant cognitive enhancers. However the lack of effect of mPFC dysfunction on OR suggests that the effect of SCPCP was not due to dysfunction of the mPFC. Furthermore, a caveat regarding the use of SOR is that it has been argued that schizophrenics are not impaired on familiarity-based item recognition as measured by SOR, but are impaired only when recollective processes are required (Huron et al. 1995; van Erp et al. 2008).

Reversal learning: Schizophrenic patients are impaired on touchscreen reversal learning, yet SCPCP in the present experiment not only did not impair 
reversal learning, it facilitated switching to the new contingency. Other researchers have similarly observed a lack of impairment following scPCP on touchscreen reversal learning (Brigman et al. 2009; Fellini et al. 2014) and in attentional set-shifting paradigms (Egerton et al. 2005; McLean et al. 2012; Rodefer et al. 2005 \& 2008). Thus to the extent that researchers wish a model to recapitulate the impairments in reversal learning seen in schizophrenia, scPCP may not be the best choice. It should be noted, however, that reversal impairments following ScPCP have been observed using other methodology, for example in operant chambers (Abdul-Monim et al. 2007; Idris et al. 2010; McLean et al. 2009 \& 2010 and in some studies using the bowl-digging version of the task (Dawson et al. 2010; however cf. Egerton et al. 2005 \& 2008; McLean et al. 2008 \& 2012; Pedersen et al. 2009; Rodefer et al. 2005 \& 2008).

To conclude, there was a double-dissociation between ScPCP and mPFC dysfunction on object-location paired associates learning and object recognition, yet similar effects on reversal learning. The pattern of impairment following ScPCP raises questions around its efficacy as a model of cognitive impairment in schizophrenia, particularly if importance is placed on the model faithfully reproducing the effects of mPFC dysfunction.

Abdul-Monim, Z., Neill, J. C., \& Reynolds, G. P. (2007). Sub-chronic psychotomimetic phencyclidine induces deficits in reversal learning and alterations in parvalbumin-immunoreactive expression in the rat. Psychopharmacology, 21(2), 198-205.

Aggleton, J. P., \& Mishkin, M. (1983). Memory impairments following restricted medial thalamic lesions in monkeys. Exp Brain Res, 52(2), 199-209.

Amitai, N., Kuczenski, R., Behrens, M. M., \& Markou, A. (2012). Repeated phencyclidine administration alters glutamate release and decreases GABA markers in the prefrontal cortex of rats. Neuropharmacology, 62(3), 1422-1431.

Andreasen, N. C., Rezai, K., Alliger, R., Swayze, V. W., 2nd, Flaum, M., Kirchner, P., et al. (1992). Hypofrontality in neuroleptic-naive patients and in patients with chronic schizophrenia. Assessment with xenon 133 single-photon emission computed tomography and the Tower of London. Arch Gen Psychiatry, 49(12), 943-958.

Arnt, J., Bang-Andersen, B., Grayson, B., Bymaster, F. P., Cohen, M. P., DeLapp, N. W., et al. (2010). Lu AE58054, a 5-HT6 antagonist, reverses cognitive impairment induced by subchronic phencyclidine in a novel object recognition test in rats. Int J Neuropsychopharmacology, 13(8), 1021-1033.

Aubin, G., Stip, E., Gelinas, I., Rainville, C., \& Chaparro, C. (2009). Daily functioning and information-processing skills among persons with schizophrenia. Psychiatric Services, 60(6), 817-822. 
Barker, G. R., Bird, F., Alexander, V., \& Warburton, E. C. (2007). Recognition memory for objects, place, and temporal order: a disconnection analysis of the role of the medial prefrontal cortex and perirhinal cortex. J Neuroscience, 27(11), 2948-2957.

Barker, G. R., \& Warburton, E. C. (2011). When Is the Hippocampus Involved in Recognition Memory? J Neuroscience, 31(29), $10721-10731$.

Barnes, S. A., Young, J. W., \& Neill, J. C. (2012). Rats tested after a washout period from sub-chronic PCP administration exhibited impaired performance in the 5-Choice Continuous Performance Test (5C-CPT) when the attentional load was increased. Neuropharmacology, 62(3), $1432-1441$.

Barnett, J. H., Sahakian, B. J., Werners, U., Hill, K. E., Brazil, R., Gallagher, O., et al. (2005). Visuospatial learning and executive function are independently impaired in first-episode psychosis. Psychol Med, 35(7), 1031-1041.

Bartok, E., Berecz, R., Glaub, T., \& Degrell, I. (2005). Cognitive functions in prepsychotic patients. Prog Neuropsychopharmacol Biol Psychiatry, 29(4), 621-625.

Beninger, R. J., Beuk, J., Banasikowski, T. J., van Adel, M., Boivin, G. A., \& Reynolds, J. N. (2010). Subchronic phencyclidine in rats: alterations in locomotor activity, maze performance, and $\mathrm{GABA}(\mathrm{A})$ receptor binding. Behav Pharmacology, 21(1), 1-10.

Bissonette, G. B., Martins, G. J., Franz, T. M., Harper, E. S., Schoenbaum, G., \& Powell, E. M. (2008). Double dissociation of the effects of medial and orbital prefrontal cortical lesions on attentional and affective shifts in mice. J Neuroscience, 28(44), 11124-11130.

Bissonette, G. B., Powell, E. M., \& Roesch, M. R. (2013). Neural structures underlying set-shifting: roles of medial prefrontal cortex and anterior cingulate cortex. Behavioural Brain Research, 250, 91-101.

Boulougouris, V., Dalley, J. W., \& Robbins, T. W. (2007). Effects of orbitofrontal, infralimbic and prelimbic cortical lesions on serial spatial reversal learning in the rat. Behavioural Brain Research, 179(2), 219228.

Brigman, J. L., Feyder, M., Saksida, L. M., Bussey, T. J., Mishina, M., \& Holmes, A. (2008). Impaired discrimination learning in mice lacking the NMDA receptor NR2A subunit. Learn Mem, 15(2), 50-54.

Brigman, J. L., Graybeal, C., \& Holmes, A. (2010). Predictably irrational: assaying cognitive inflexibility in mouse models of schizophrenia. Front Neuroscience, 4.

Brigman, J. L., Ihne, J., Saksida, L. M., Bussey, T. J., \& Holmes, A. (2009). Effects of Subchronic Phencyclidine (PCP) Treatment on Social Behaviors, and Operant Discrimination and Reversal Learning in C57BL/6J Mice. Front Behav Neuroscience, 3, 2. 
Brigman, J. L., Padukiewicz, K. E., Sutherland, M. L., \& Rothblat, L. A. (2006). Executive functions in the heterozygous reeler mouse model of schizophrenia. Behav Neuroscience, 120(4), 984-988.

Brown, V. J., \& Bowman, E. M. (2002). Rodent models of prefrontal cortical function. Trends Neuroscience, 25(7), 340-343.

Burke, K. A., Takahashi, Y. K., Correll, J., Leon Brown, P., \& Schoenbaum, G. (2009). Orbitofrontal inactivation impairs reversal of Pavlovian learning by interfering with 'disinhibition' of responding for previously unrewarded cues. Eur J Neuroscience, 30(10), 1941-1946.

Bussey, T. J., Barch, D. M., \& Baxter, M. G. (2013). Testing long-term memory in animal models of schizophrenia: suggestions from CNTRICS. Neurosci Biobehav Rev, 37(9 Pt B), 2141-2148.

Bussey, T. J., Muir, J. L., Everitt, B. J., \& Robbins, T. W. (1997). Triple dissociation of anterior cingulate, posterior cingulate, and medial frontal cortices on visual discrimination tasks using a touchscreen testing procedure for the rat. Behav Neuroscience, 111(5), 920-936.

Bussey, T. J., Padain, T. L., Skillings, E., Winters, B. D., Morton, A. J., \& Saksida, L. M. (2008). The touchscreen cognitive testing method for rodents: How to get the best out of your rat. Learn Mem, 15(7), 516523.

Bussey, T. J., Saksida, L. M., \& Murray, E. A. (2003). Impairments in visual discrimination after perirhinal cortex lesions: testing 'declarative' vs. 'perceptual-mnemonic' views of perirhinal cortex function. Eur $\mathrm{J}$ Neuroscience, 17(3), 649-660.

Carter, C. S., Perlstein, W., Ganguli, R., Brar, J., Mintun, M., \& Cohen, J. D. (1998). Functional hypofrontality and working memory dysfunction in schizophrenia. Am J Psychiatry, 155(9), 1285-1287.

Castner, S. A., Goldman-Rakic, P. S., \& Williams, G. V. (2004). Animal models of working memory: insights for targeting cognitive dysfunction in schizophrenia. Psychopharmacology), 174(1), 111-125.

Choi, Y. K., Snigdha, S., Shahid, M., Neill, J. C., \& Tarazi, F. I. (2009). Subchronic effects of phencyclidine on dopamine and serotonin receptors: implications for schizophrenia. J Mol Neuroscience, 38(3), 227-235.

Chudasama, Y., Bussey, T. J., \& Muir, J. L. (2001). Effects of selective thalamic and prelimbic cortex lesions on two types of visual discrimination and reversal learning. European Journal of Neuroscience, 14, 1009-1020.

Chudasama, Y., \& Robbins, T. W. (2003). Dissociable contributions of the orbitofrontal and infralimbic cortex to pavlovian autoshaping and discrimination reversal learning: further evidence for the functional heterogeneity of the rodent frontal cortex. $J$ Neuroscience, 23(25), 8771-8780.

Dawson, N., Thompson, R. J., McVie, A., Thomson, D. M., Morris, B. J., \& Pratt, J. A. (2010). Modafinil Reverses Phencyclidine-Induced Deficits 
in Cognitive Flexibility, Cerebral Metabolism, and Functional Brain Connectivity. Schizophr Bulletin.

de Rover, M., Pironti, V. A., McCabe, J. A., Acosta-Cabronero, J., Arana, F. S., Morein-Zamir, S., et al. (2011). Hippocampal dysfunction in patients with mild cognitive impairment: a functional neuroimaging study of a visuospatial paired associates learning task. Neuropsychologia, 49(7), 2060-2070.

Dere, E., Huston, J. P., \& De Souza Silva, M. A. (2007). The pharmacology, neuroanatomy and neurogenetics of one-trial object recognition in rodents. Neurosci Biobehav Rev, 31(5), 673-704.

Dias, R., Robbins, T. W., \& Roberts, A. C. (1996). Primate analogue of the Wisconsin Card Sorting Test: effects of excitotoxic lesions of the prefrontal cortex in the marmoset. Behav Neuroscience, 110(5), 872886.

Dias-Ferreira, E., Sousa, J. C., Melo, I., Morgado, P., Mesquita, A. R., Cerqueira, J. J., et al. (2009). Chronic stress causes frontostriatal reorganization and affects decision-making. Science, 325(5940), 621625.

Domino, E. F., \& Luby, E. D. (2012). Phencyclidine/Schizophrenia: One View Toward the Past, The Other to the Future. Schizophr Bulletin.

Donohoe, G., Spoletini, I., McGlade, N., Behan, C., Hayden, J., O'Donoghue, T., et al. (2008). Are relational style and neuropsychological performance predictors of social attributions in chronic schizophrenia? Psychiatry Res, 161(1), 19-27.

Egerton, A., Reid, L., McKerchar, C. E., Morris, B. J., \& Pratt, J. A. (2005). Impairment in perceptual attentional set-shifting following PCP administration: a rodent model of set-shifting deficits in schizophrenia. Psychopharmacology, 179(1), 77-84.

Egerton, A., Reid, L., McGregor, S., Cochran, S., Morris, B. J., \& Pratt, J. A. (2008). Subchronic and chronic PCP treatment produces temporally distinct deficits in attentional set shifting and prepulse inhibition in rats. Psychopharmacology, 198(1), 37-49.

Ennaceur, A., Neave, N., \& Aggleton, J. P. (1997). Spontaneous object recognition and object location memory in rats: the effects of lesions in the cingulate cortices, the medial prefrontal cortex, the cingulum bundle and the fornix. Exp Brain Research, 113(3), 509-519.

Fellini, L., Kumar, G., Gibbs, S., Steckler, T., \& Talpos, J. (2014). Reevaluating the PCP challenge as a pre-clinical model of impaired cognitive flexibility in schizophrenia. Eur Neuropsychopharmacology, 24(11), 1836-1849.

Forwood, S. E., Winters, B. D., \& Bussey, T. J. (2005). Hippocampal lesions that abolish spatial maze performance spare object recognition memory at delays of up to 48 hours. Hippocampus, 15(3), 347-355. 
Gilmour, G., Arguello, A., Bari, A., Brown, V. J., Carter, C., Floresco, S. B., et al. (2013). Measuring the construct of executive control in schizophrenia: defining and validating translational animal paradigms for discovery research. Neurosci Biobehav Rev, 37(9 Pt B), 2125-2140.

Glahn, D. C., Ragland, J. D., Abramoff, A., Barrett, J., Laird, A. R., Bearden, C. E., et al. (2005). Beyond hypofrontality: a quantitative meta-analysis of functional neuroimaging studies of working memory in schizophrenia. Hum Brain Mapping, 25(1), 60-69.

Graybeal, C., Feyder, M., Schulman, E., Saksida, L. M., Bussey, T. J., Brigman, J. L., et al. (2011). Paradoxical reversal learning enhancement by stress or prefrontal cortical damage: rescue with BDNF. Nature Neuroscience, 14, 1507-1509.

Grayson, B., Adamson, L., Harte, M., Leger, M., Marsh, S., Piercy, C., et al. (2014). The involvement of distraction in memory deficits induced by NMDAR antagonism: relevance to cognitive deficits in schizophrenia. Behavioural Brain Research, 266, 188-192.

Grayson, B., Idris, N. F., \& Neill, J. C. (2007). Atypical antipsychotics attenuate a sub-chronic PCP-induced cognitive deficit in the novel object recognition task in the rat. Behavioural Brain Research, 184(1), 31-38.

Hannesson, D. K., Howland, J. G., \& Phillips, A. G. (2004). Interaction between Perirhinal and Medial Prefrontal Cortex Is Required for Temporal Order But Not Recognition Memory for Objects in Rats. $J$ Neuroscience, 24(19), 4569-4606.

Haring, L., Mottus, R., Koch, K., Trei, M., \& Maron, E. (2014). Factorial validity, measurement equivalence and cognitive performance of the Cambridge Neuropsychological Test Automated Battery (CANTAB) between patients with first-episode psychosis and healthy volunteers. Psychol Medicine 1-11.

Hill, K., Mann, L., Laws, K. R., Stephenson, C. M., Nimmo-Smith, I., \& McKenna, P. J. (2004). Hypofrontality in schizophrenia: a metaanalysis of functional imaging studies. Acta Psychiatr Scand, 110(4), 243-256.

Horiguchi, M., Huang, M., \& Meltzer, H. Y. (2011). Interaction of mGlu2/3 agonism with clozapine and lurasidone to restore novel object recognition in subchronic phencyclidine-treated rats.

Psychopharmacology), 217(1), 13-24.

Horner, A. E., Heath, C. J., Hvoslef-Eide, M., Kent, B. A., Kim, C. H., Nilsson, S. R., et al. (2013). The touchscreen operant platform for testing learning and memory in rats and mice. Nature Protocols, 8(10), 19611984.

Howes, O., McCutcheon, R., \& Stone, J. (2015). Glutamate and dopamine in schizophrenia: an update for the 21st century. Psychopharmacology, 29(2), 97-115. 
Huron, C., Danion, J., Giacomoni, F., \& Grange, D. (1995). Impairment of recognition memory with, but not without, conscious recollection in schizophrenia. American Journal of Psychiatry, 152(2), 1737-1742.

Idris, N., Neill, J., Grayson, B., Bang-Andersen, B., Witten, L. M., Brennum, L. T., et al. (2010). Sertindole improves sub-chronic PCP-induced reversal learning and episodic memory deficits in rodents: involvement of 5-HT(6) and 5-HT (2A) receptor mechanisms. Psychopharmacology, 208(1), 23-36.

Ingvar, D. H., \& Franzen, G. (1974). Abnormalities of cerebral blood flow distribution in patients with chronic schizophrenia. Acta Psychiatr Scand, 50(4), 425-462.

Itil, T., Keskiner, A., Kiremitci, N., \& Holden, J. M. (1967). Effect of phencyclidine in chronic schizophrenics. Can Psychiatr Assoc J, 12(2), 209-212.

Javitt, D. C., \& Zukin, S. R. (1991). Recent advances in the phencyclidine model of schizophrenia. Am J Psychiatry, 148(10), 1301-1308.

Javitt, D. C., Zukin, S. R., Heresco-Levy, U., \& Umbricht, D. (2012). Has an Angel Shown the Way? Etiological and Therapeutic Implications of the PCP/NMDA Model of Schizophrenia. Schizophrenia Bulletin, 38(5), 958-966.

Kim, C.H., Heath, C.J., Kent, B.A., Bussey, T.J., Saksida, L.M. (2015). The role of the dorsal hippocampus in two versions of the touchscreen automated paired associates learning (PAL) task for mice. Psychopharmacology, in press.

Krystal, J. H., Karper, L. P., Seibyl, J. P., Freeman, G. K., Delaney, R., Bremner, J. D., et al. (1994). Subanesthetic effects of the noncompetitive NMDA receptor antagonist, ketamine, in humans: Psychotomimetic, perceptual, cognitive, and neuroendro- crine responses. Arch Gen Psychiatry, 51, 199-214.

Lahti, A. C., Koffel, B., LaPorte, D., \& Tamminga, C. A. (1995). Subanesthetic doses of ketamine stimulate psychosis in schizophrenia. Neuropsychopharmacology, 13(1), 9-19.

Lahti, A. C., Weiler, M. A., Tamara Michaelidis, B. A., Parwani, A., \& Tamminga, C. A. (2001). Effects of ketamine in normal and schizophrenic volunteers. Neuropsychopharmacology, 25(4), 455-467.

Laurent, V., \& Podhorna, J. (2004). Subchronic phencyclidine treatment impairs performance of C57BL/6 mice in the attentional set-shifting task. Behav Pharmacology, 15(2), 141-148.

Le Cozannet, R., Fone, K. C., \& Moran, P. M. (2010). Phencyclidine withdrawal disrupts episodic-like memory in rats: reversal by donepezil but not clozapine. Int J Neuropsychopharmacology, 13(8), 1011-1020.

Leeson, V. C., Robbins, T. W., Matheson, E., Hutton, S. B., Ron, M. A., Barnes, T. R., et al. (2009). Discrimination learning, reversal, and setshifting in first-episode schizophrenia: stability over six years and 
specific associations with medication type and disorganization syndrome. Biol Psychiatry, 66(6), 586-593.

Lyon, L., Saksida, L. M., \& Bussey, T. J. (2012). Spontaneous object recognition and its relevance to schizophrenia: a review of findings from pharmacological, genetic, lesion and developmental rodent models. Psychopharmacology, 220(4), 647-672.

Malhotra, A. K., Pinals, D. A., Adler, C. M., Elman, I., Clifton, A., Pickar, D., et al. (1997). Ketamine-induced exacerbation of psychotic symptoms and cognitive impairment in neuroleptic-free schizophrenics. Neuropsychopharmacology, 17(3), 141-150.

Malhotra, A. K., Pinals, D. A., Weingartner, H., Sirocco, K., Missar, C. D., Pickar, D., et al. (1996). NMDA receptor function and human cognition: the effects of ketamine in healthy volunteers. Neuropsychopharmacology, 14(5), 301-307.

McAllister, K.A.L., Saksida, L.M., Busset, T.J. (2013). Dissociation between memory retention across a delay and pattern separation following medial prefrontal cortex lesions in the touchscreen TUNL task. Neurobiology Learn Mem, 101, 120-126.

McAlonan, K., \& Brown, V. J. (2003). Orbital prefrontal cortex mediates reversal learning and not attentional set shifting in the rat. Behavioural Brain Research, 146(1-2), 97-103.

McKibben, C. E., Jenkins, T. A., Adams, H. N., Harte, M. K., \& Reynolds, G. P. (2010). Effect of pretreatment with risperidone on phencyclidineinduced disruptions in object recognition memory and prefrontal cortex parvalbumin immunoreactivity in the rat. Behavioural Brain Research, 208(1), 132-136.

McKirdy, J., Sussmann, J. E., Hall, J., Lawrie, S. M., Johnstone, E. C., \& Mclntosh, A. M. (2009). Set shifting and reversal learning in patients with bipolar disorder or schizophrenia. Psychol Medicine, 39(8), 12891293.

McLean, S. L., Beck, J. P., Woolley, M. L., Neill, J. C., (2008). A preliminary investigation into the effects of antipsychotics on sub-chronic phencyclidine-induced deficits in attentional set-shifting in female rats. Behav Brain Research, 189(1), 152-158.

McLean, S. L., Idris, N. F., Grayson, B., Gendle, D. F., Mackie, C., Lesage, A. S., et al. (2012). PNU-120596, a positive allosteric modulator of alpha7 nicotinic acetylcholine receptors, reverses a sub-chronic phencyclidineinduced cognitive deficit in the attentional set-shifting task in female rats. Psychopharmacology, 26(9), 1265-1270.

McLean, S. L., Idris, N. F., Woolley, M. L., \& Neill, J. C. (2009). D1-like receptor activation improves $\mathrm{PCP}$-induced cognitive deficits in animal models: Implications for mechanisms of improved cognitive function in schizophrenia. European Neuropsychopharmacology, 19(6), 440-450.

McLean, S. L., Neill, J. C., Idris, N. F., Marston, H. M., Wong, E. H., \& Shahid, M. (2010). Effects of asenapine, olanzapine, and risperidone on 
psychotomimetic-induced reversal-learning deficits in the rat. Behavioural Brain Research, 214(2), 240-247.

Meltzer, H. Y., Rajagopal, L., Huang, M., Oyamada, Y., Kwon, S., \& Horiguchi, M. (2013). Translating the N-methyl-D-aspartate receptor antagonist model of schizophrenia to treatments for cognitive impairment in schizophrenia. Int J Neuropsychopharmacology, 16(10), 2181-2194.

Minzenberg, M. J., \& Carter, C. S. (2012). Developing treatments for impaired cognition in schizophrenia. Trends Cogn Sci, 16(1), 35-42.

Mumby, D. G., Pinel, J. P., \& Dastur, F. N. (1993). Mediodorsal thalamic lesions and object recognition in rats. Psychobiology, 21(1), 27-36.

Murray, G. K., Cheng, F., Clark, L., Barnett, J. H., Blackwell, A. D., Fletcher, P. C., et al. (2008). Reinforcement and reversal learning in first-episode psychosis. Schizophr Bulletin, 34(5), 848-855.

Neill, J. C., Barnes, S., Cook, S., Grayson, B., Idris, N. F., McLean, S. L., et al. (2010). Animal models of cognitive dysfunction and negative symptoms of schizophrenia: focus on NMDA receptor antagonism. Pharmacol Ther, 128(3), 419-432.

Neill, J. C., Harte, M. K., Haddad, P. M., Lydall, E. S., \& Dwyer, D. M. (2014). Acute and chronic effects of NMDA receptor antagonists in rodents, relevance to negative symptoms of schizophrenia: a translational link to humans. Eur Neuropsychopharmacology, 24(5), 822-835.

Nestler, E. J., \& Hyman, S. E. (2010). Animal models of neuropsychiatric disorders. Nat Neurosci, 13(10), 1161-1169.

Nithianantharajah, J., \& Grant, S. G. (2013). Cognitive components in mice and humans: combining genetics and touchscreens for medical translation. Neurobiol Learn Mem, 105, 13-19.

Owen, A. M., Sahakian, B. J., Semple, J., Polkey, C. E., \& Robbins, T. W. (1995). Visuo-spatial short-term recognition memory and learning after temporal lobe excisions, frontal lobe excisions or amygdalohippocampectomy in man. Neuropsychologia, 33(1), 1-24.

Oyamada, Y., Horiguchi, M., Rajagopal, L., Miyauchi, M., \& Meltzer, H. Y. (2015). Combined serotonin (5-HT)1A agonism, 5-HT2A and dopamine D2 receptor antagonism reproduces atypical antipsychotic drug effects on phencyclidine-impaired novel object recognition in rats. Behavioural Brain Research, 285, 165-175.

Paxinos, G., \& Watson, C. (2007). The Rat Brain in Stereotaxic Coordinates. London, UK: Academic Press.

Pedersen, C.S., Goetghebeur, P., Dias, R. (2009). Chronic infusion of PCP via osmotic mini-pumps: A new rodent model of cognitive deficit in schizophrenia characterized by impaired attentional set-shifting (ID/ED) performance. Journal of Neuroscience Methods, 185(1), 66-69.

Poels, E. M., Kegeles, L. S., Kantrowitz, J. T., Slifstein, M., Javitt, D. C., Lieberman, J. A., et al. (2014). Imaging glutamate in schizophrenia: 
review of findings and implications for drug discovery. Mol Psychiatry, 19(1), 20-29.

Ragozzino, M. E. (2007). The contribution of the medial prefrontal cortex, orbitofrontal cortex, and dorsomedial striatum to behavioral flexibility. Ann N Y Acad Sci, 1121, 355-375.

Ragozzino, M. E., Jih, J., \& Tzavos, A. (2002). Involvement of the dorsomedial striatum in behavioral flexibility: role of muscarinic cholinergic receptors. Brain Research, 953(1-2), 205-214.

Rodefer, J. S., Murphy, E. R., \& Baxter, M. G. (2005). PDE10A inhibition reverses subchronic $\mathrm{PCP}$-induced deficits in attentional set-shifting in rats. Eur J Neuroscience, 21(4), 1070-1076.

Rodefer, J. S., Nguyen, T. N., Karlsson, J. J., \& Arnt, J. (2008). Reversal of subchronic PCP-induced deficits in attentional set shifting in rats by sertindole and a 5-HT6 receptor antagonist: comparison among antipsychotics. Neuropsychopharmacology, 33(11), 2657-2666.

Sahakian, B. J., Morris, R. G., Evenden, J. L., Heald, A., Levy, R., Philpot, M., et al. (1988). A Comparative-Study of Visuospatial Memory and Learning in Alzheimer-Type Dementia and Parkinsons-Disease. Brain, 111, 695-718.

Schaefer, J., Giangrande, E., Weinberger, D. R., \& Dickinson, D. (2013). The global cognitive impairment in schizophrenia: consistent over decades and around the world. Schizophr Res, 150(1), 42-50.

Schlagenhauf, F., Huys, Q. J., Deserno, L., Rapp, M. A., Beck, A., Heinze, H. J., et al. (2014). Striatal dysfunction during reversal learning in unmedicated schizophrenia patients. Neuroimage, 89, 171-180.

Singh, S. P., \& Singh, V. (2011). Meta-analysis of the efficacy of adjunctive NMDA receptor modulators in chronic schizophrenia. CNS Drugs, 25(10), 859-885.

Snigdha, S., Horiguchi, M., Huang, M., Li, Z., Shahid, M., Neill, J. C., et al. (2010). Attenuation of phencyclidine-induced object recognition deficits by the combination of atypical antipsychotic drugs and pimavanserin (ACP 103), a 5-hydroxytryptamine(2A) receptor inverse agonist. $J$ Pharmacol Exp Ther, 332(2), 622-631.

Snigdha, S., Idris, N., Grayson, B., Shahid, M., \& Neill, J. C. (2011). Asenapine improves phencyclidine-induced object recognition deficits in the rat: evidence for engagement of a dopamine D1 receptor mechanism. Psychopharmacology, 214(4), 843-853.

Snyder, S. H. (1980). Phencyclidine. Nature, 285(5764), 355-356.

Talpos, J. C., Dias, R., Bussey, T. J., \& Saksida, L. M. (2008). Hippocampal lesions in rats impair learning and memory for locations on a touchsensitive computer screen: the "ASAT" task. Behavioural Brain Research, 192(2), 216-225.

Talpos, J. C., Winters, B. D., Dias, R., Saksida, L. M., \& Bussey, T. J. (2009). A novel touchscreen-automated paired-associate learning (PAL) task 
sensitive to pharmacological manipulation of the hippocampus: a translational rodent model of cognitive impairments in neurodegenerative disease. Psychopharmacology, 205(1), 157-168.

Tamminga, C. A. (1998). Schizophrenia and glutamatergic transmission. Crit Rev Neurobiol, 12(1-2), 21-36.

van Erp, T. G., Lesh, T. A., Knowlton, B. J., Bearden, C. E., Hardt, M., Karlsgodt, K. H., et al. (2008). Remember and know judgments during recognition in chronic schizophrenia. Schizophr Res, 100(1-3), 181190.

Vingerhoets, W. A., Bloemen, O. J., Bakker, G., \& van Amelsvoort, T. A. (2013). Pharmacological Interventions for the MATRICS Cognitive Domains in Schizophrenia: What's the Evidence? Front Psychiatry, 4, 157.

Waltz, J. A., \& Gold, J. M. (2007). Probabilistic reversal learning impairments in schizophrenia: further evidence of orbitofrontal dysfunction. Schizophr Res, 93(1-3), 296-303.

Winters, B. D., Bartko, S. J., Saksida, L. M., \& Bussey, T. J. (2010). Muscimol, AP5, or scopolamine infused into perirhinal cortex impairs two-choice visual discrimination learning in rats. Neurobiology Learn Memory, 93(2), 221-228.

Wood, S. J., Proffitt, T., Mahony, K., Smith, D. J., Buchanan, J. A., Brewer, W., et al. (2002). Visuospatial memory and learning in first-episode schizophreniform psychosis and established schizophrenia: a functional correlate of hippocampal pathology? Psychol Med, 32(3), 429-438.

Young, A. M., Stubbendorff, C., Valencia, M., \& Gerdjikov, T. V. (2015). Disruption of medial prefrontal synchrony in the subchronic phencyclidine model of schizophrenia in rats. Neuroscience, 287, 157163.

Zhuo, J. M., Prescott, S. L., Murray, M. E., Zhang, H. Y., Baxter, M. G., \& Nicolle, M. M. (2007). Early discrimination reversal learning impairment and preserved spatial learning in a longitudinal study of Tg2576 APPsw mice. Neurobiol Aging, 28(8), 1248-1257. 


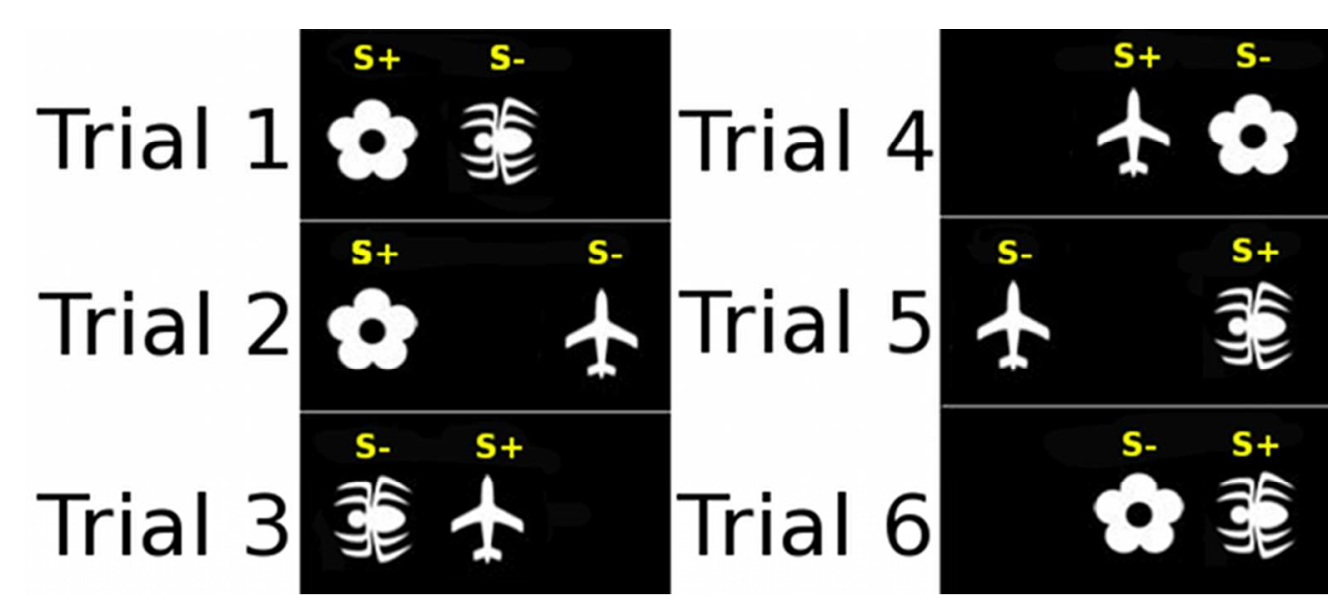

Fig. 1 Trial-types in touchscreen object-location paired-associates learning (dPAL left and sPAL right). S+ rewarded; S- results in 'time out'. Adapted from Talpos et al (2009). $83 \times 36 \mathrm{~mm}(300 \times 300$ DPI $)$ 


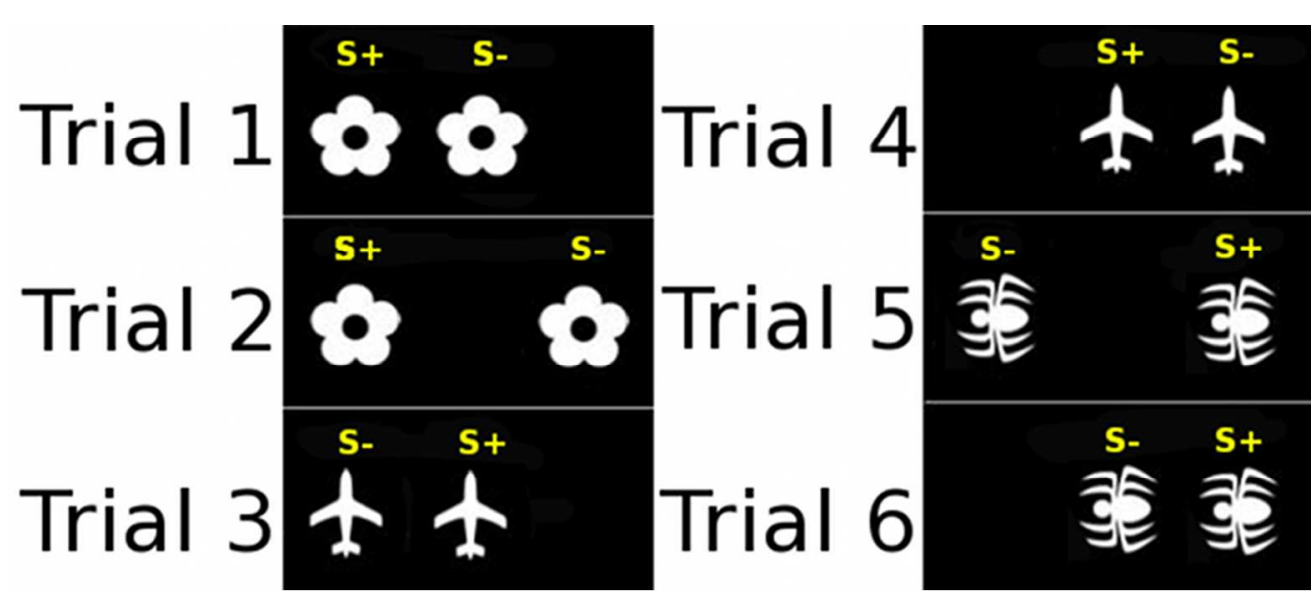

Fig. 1 Trial-types in touchscreen object-location paired-associates learning (dPAL left and SPAL right). S+ rewarded; S- results in 'time out'. Adapted from Talpos et al (2009). $83 \times 36 \mathrm{~mm}(300 \times 300 \mathrm{DPI})$ 
Fig. 3 mPFC lesions in PAL. Damage common to all subjects in solid black, with maximum extent of any damage shown by the black line. Coronal sections at $3.72 \mathrm{~mm}, 2.76 \mathrm{~mm}$, and $1.08 \mathrm{~mm}$ anterior to Bregma. Images adapted from Paxinos and Watson (2007). Composite photomicrograph presents contrast between sham (left) and lesion (right) for demonstration purposes. $41 \times 73 \mathrm{~mm}(300 \times 300 \mathrm{DPI})$ 


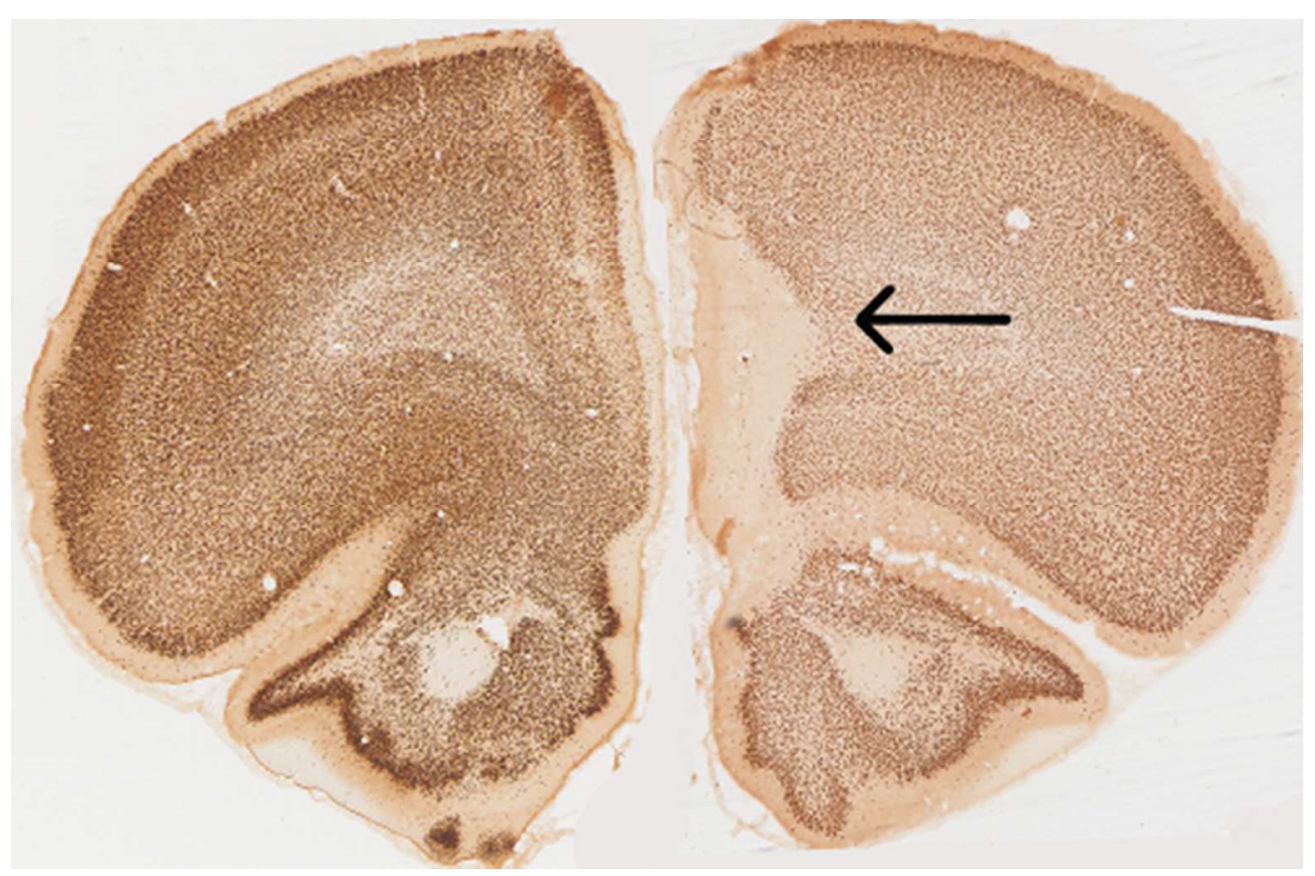

Fig. 3 mPFC lesions in PAL. Damage common to all subjects in solid black, with maximum extent of any damage shown by the black line. Coronal sections at $3.72 \mathrm{~mm}, 2.76 \mathrm{~mm}$, and $1.08 \mathrm{~mm}$ anterior to Bregma. Images adapted from Paxinos and Watson (2007). Composite photomicrograph presents contrast between sham (left) and lesion (right) for demonstration purposes. $41 \times 27 \mathrm{~mm}(300 \times 300 \mathrm{DPI})$ 
Fig. $8 \mathrm{mPFC}$ lesions in reversal learning. Damage common to all subjects in solid black, with maximum extent of any damage shown by the black line. Coronal sections are taken at $3.72 \mathrm{~mm}, 2.76 \mathrm{~mm}$, and $1.08 \mathrm{~mm}$ anterior to Bregma. Images adapted from Paxinos and Watson (2007). Composite photomicrograph presents a contrast between sham (left) and lesion (right) for demonstration purposes. $41 \times 79 \mathrm{~mm}(300 \times 300 \mathrm{DPI})$ 
Fig. $8 \mathrm{mPFC}$ lesions in reversal learning. Damage common to all subjects in solid black, with maximum extent of any damage shown by the black line. Coronal sections are taken at $3.72 \mathrm{~mm}, 2.76 \mathrm{~mm}$, and $1.08 \mathrm{~mm}$ anterior to Bregma. Images adapted from Paxinos and Watson (2007). Composite photomicrograph presents a contrast between sham (left) and lesion (right) for demonstration purposes. $41 \times 31 \mathrm{~mm}(300 \times 300 \mathrm{DPI})$ 
scPCP and Reversal

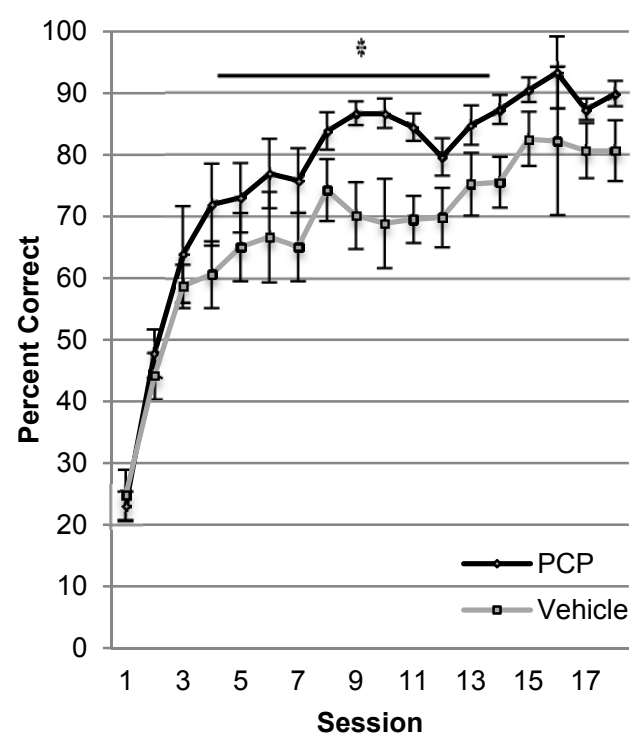

Sessions to Cri

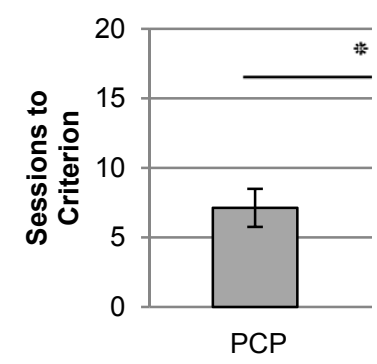

Errors to Critel

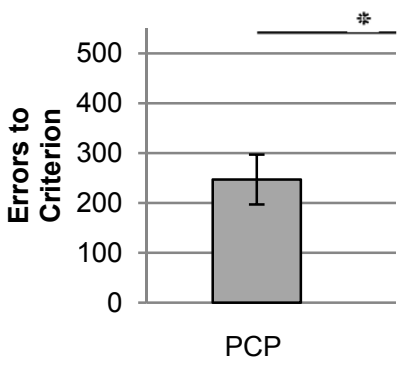


1

2

3

4

5

6

7

8

9

10

11

13

14

15

16

17

18

19

20

21

22

23

24

25

26

27

28

29

30

31

32

33

34

35

36

37

38

39

40

41

42

43

44

45

46

47

48

49

50

51

52

53

54

55

56

57

58

59

60 terion

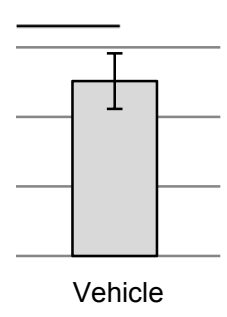

rion

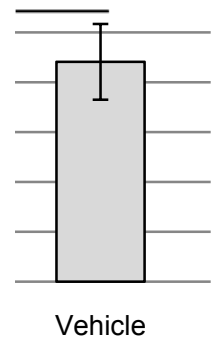



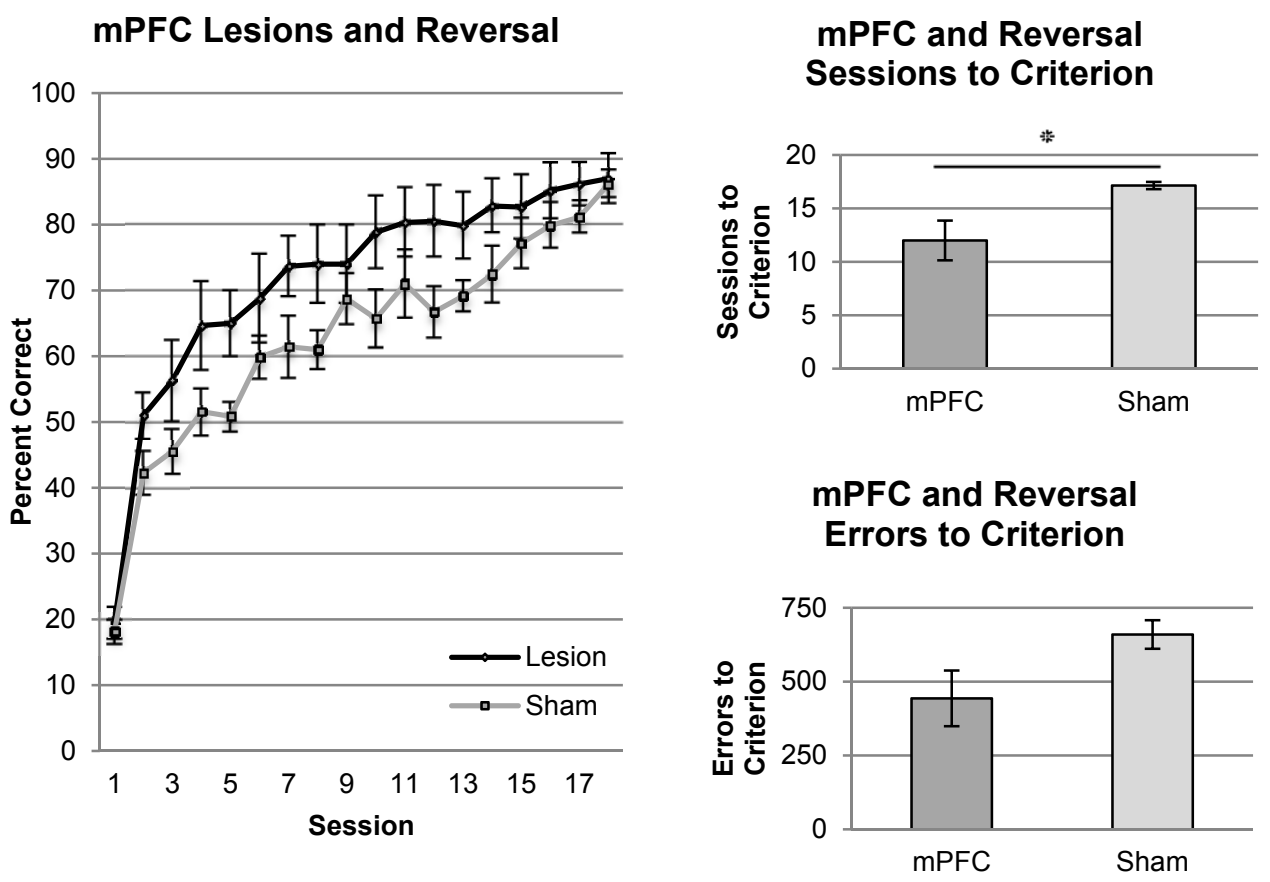